\title{
Patrimonio cultural prehispánico y peligro geodinámico en el valle del Huatanay - Cusco
}

Patrimoine culturel pré-hispanique et aléa géodynamique dans la vallée du Huatanay, Cusco

Pre-hispanic archeological heritage and geodynamic hazard in the valley of Huatanay - Cuzco

\section{Raúl Carreño Collatupa}

\section{OpenEdition}

Journals

Edición electrónica

URL: http://journals.openedition.org/bifea/5580

DOI: $10.4000 /$ bifea.5580

ISSN: 2076-5827

\section{Editor}

Institut Français d'Études Andines

\section{Edición impresa}

Fecha de publicación: 1 mayo 2005

Paginación: 35-57

ISSN: 0303-7495

\section{Referencia electrónica}

Raúl Carreño Collatupa, «Patrimonio cultural prehispánico y peligro geodinámico en el valle del Huatanay - Cusco », Bulletin de l'Institut français d'études andines [En línea], 34 (1) | 2005, Publicado el 08 abril 2005, consultado el 02 diciembre 2020. URL : http://journals.openedition.org/bifea/5580 ; DOI : https://doi.org/10.4000/bifea.5580

Este documento fue generado automáticamente el 2 diciembre 2020.

Les contenus du Bulletin de l'Institut français d'études andines sont mis à disposition selon les termes de la licence Creative Commons Attribution - Pas d'Utilisation Commerciale - Pas de Modification 4.0 International. 


\section{Patrimonio cultural prehispánico y peligro geodinámico en el valle del Huatanay - Cusco*}

Patrimoine culturel pré-hispanique et aléa géodynamique dans la vallée du Huatanay, Cusco

Pre-hispanic archeological heritage and geodynamic hazard in the valley of

Huatanay - Cuzco

Raúl Carreño Collatupa

1 Una de las leyendas sobre la fundación del Cusco, la de los hermanos Ayar, relata que la envidia y el temor que causaba el potente hondero Ayar Kachi hicieron que sus hermanos, con engaños, lo encerraran y abandonaran en una cueva del cerro Huanacaure. La furia del prisionero, antes de convertirse en un ave fabulosa, fue tal que «[...] la tierra tembló en tanta manera que se hundieron muchos cerros, cayendo sobre los valles». (Cieza de León, 1977 [1553])

2 La anterior, aunque mítica, constituye la más antigua alusión a los fenómenos de geodinámica en el Cusco. Como todo mito, el de Ayar Kachi debe estar basado en un hecho real, pues es bien conocida la secuela de violentos eventos de geodinámica externa que los grandes sismos generan. De todos modos, no lejos del Huanacaure, al sureste de la ciudad del Cusco, se encuentran grandes deslizamientos como los de Ranraqasa y Pomate (Yaurisque), Saylla-Ch'akiqocha o Huaynapicol (Carreño, 1998a). La leyenda pone en evidencia que los antiguos cusqueños conocían bien el carácter fuertemente dinámico de la cuenca que habitaban y eso los indujo a desarrollar una ingeniería de tratamiento y prevención que, en muchos casos, y hasta la actualidad, muestra su eficacia, aunque ésta se ve comprometida por la falta de mantenimiento, la destrucción paulatina de algunos elementos claves de los sistemas hidráulicos, por el avance de procesos de erosión y la incesante acción humana, a través de la expansión urbana y la sobre-explotación de ciertos recursos de montaña. 
3 Presentamos un resumen de los resultados preliminares del análisis de fenómenos de inestabilidad de masas que afectan parte del patrimonio precolombino del valle del Huatanay o Cusco. Por su ubicación en laderas y mesetas, los grupos arqueológicos estudiados están exentos del peligro torrencial, a excepción de su faceta de socavación. Los mecanismos y cinemática de los fenómenos de dinámica lenta pero permanente (como los deslizamientos gigantes, Sagging, Spread o deriva de bloques, karstificación) han inducido a errores de interpretación y tipificación lo cual atenta contra la correcta evaluación de su peligrosidad (PROEPTI-EPFL, 2001).

4 La evaluación se inició entre 1995 y 1998, con el Proyecto de estudio y prevención de desastres relacionados a terrenos inestables (PROEPTI) de la Escuela Politécnica Federal de Lausana - Suiza (EPFL). Entre 1999 y 2002 se hicieron observaciones adicionales, como contribución al Programa IGCP-425 «Patrimonio cultural y peligros por deslizamientos», iniciativa patrocinada por UNESCO y la Unión Internacional de Ciencias Geológicas (IUGS). En la actualidad, el GRUDEC AYAR, dentro del Programa Internacional de Deslizamientos (IPL) del Internacional Consortium on Landslides, lleva adelante un proyecto más amplio para evaluar los peligros que afectan o amenazan al patrimonio cultural monumental en la región del cusco y Apurímac.

\section{Marco geológico y relaciones genéticas de los fenómenos de inestabilidad}

En la cuenca del Huatanay afloran diversas unidades geológicas que muestran diferentes niveles de susceptibilidad geodinámica bajo control litológico y/o estructural. Mencionamos las que tienen relación directa con los sitios estudiados (fig. 1).

Figura 1 - Esquema geológico de la cuenca del Huatanay (modificado de Mendívil \& Dávila, 1994, y Cabrera, 1988) y ubicación de los sitios arqueológicos evaluados

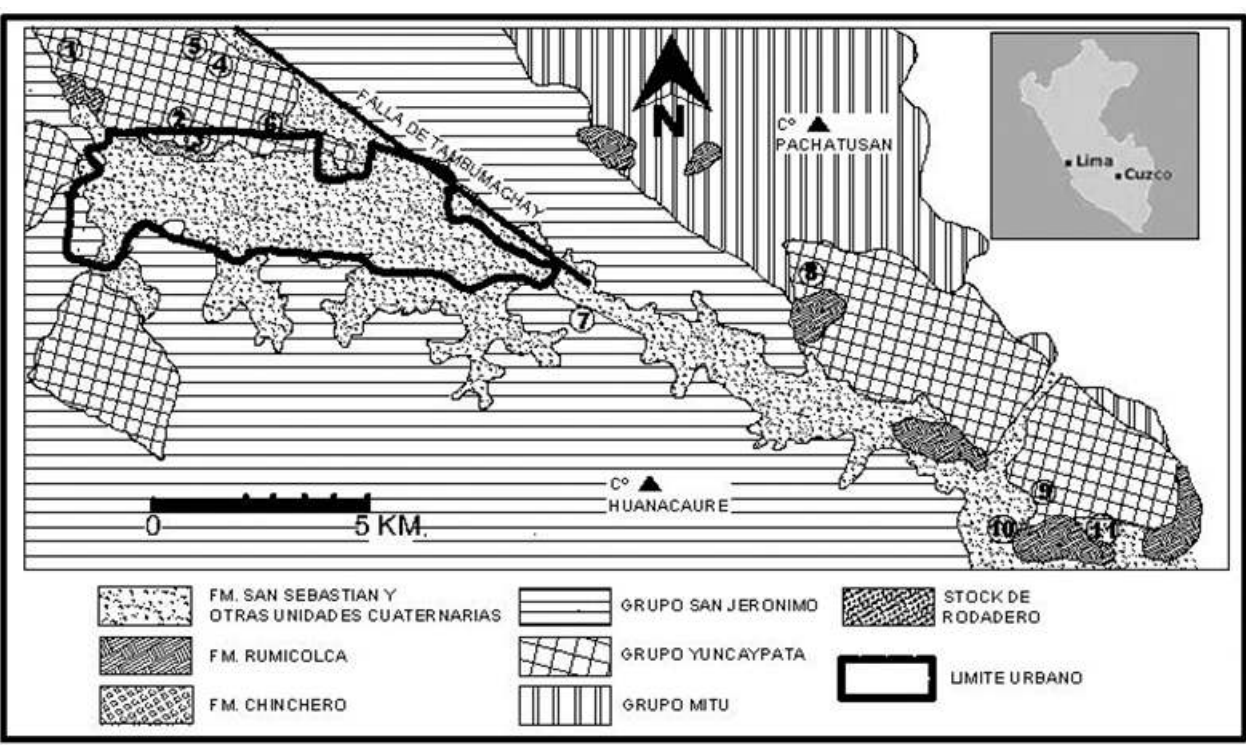

1: Saqsayhuaman-Chakán; 2: K'enqo; 3: Mosoqllaqta; 4: Tambumachay; 5: Pukapukara; 6: Choquekiraopujyo; 7: Sillkinchan; 8: Tipón; 9: Urpikancha; 10: Rumicolca; 11: Pikillaqta 
6 Grupo Yuncaypata: unidad cretácica del Albiano-Maestrichtiano: calizas, capas rojas marinas y evaporitas muy susceptibles a formar deslizamientos, especialmente de tipo rotacional, que luego evolucionan hacia mecanismos complejos, pero que tienen poca tendencia a generar episodios violentos, debido a que en su estilo cinemático predominan deformaciones plásticas, que son aliviadas por la erosión fluvial (evacuación rápida de derrubios que caen dentro de las corrientes). Es posible que en el origen de varios deslizamientos haya habido influencia de procesos kársticos. Sus afloramientos están concentrados al norte y oeste de la cuenca.

7 Las calizas descansan sobre horizontes de pelitas y yesos, estando afectadas por fenómenos de Spread, Blockslide o deriva de bloques. De los tres tipos de caliza (compacta negra y gris, arenosa con estratificación delgada, y brechosa) que señala Kalafatovich (1957), las empleadas en las construcciones inkas son las descritas como compactas de color gris y que forman los «islotes» o afloramientos dispersos derivados del Spread. Las otras calizas no presentan buenas cualidades geomecánicas y fueron desdeñadas por los inkas.

8 Grupo San Jerónimo: unidad terciaria (Eoceno-Oligoceno) que continúa siendo objeto de controversias sobre sus divisiones y origen. Mendívil \& Dávila (1994) la denominan Grupo Chitapampa. Se trata de capas rojas continentales relativamente menos susceptibles a formar deslizamientos. Cuando se dan, son de grandes dimensiones y evidencian control estructural, en pendientes conformes o estructuras de Toppling (doblamiento o alabeo de capas y ulterior formación de un plano de ruptura en la zona de flexión). Aflora al norte, sur y suroeste de la cuenca. Los episodios de deslizamiento paroxismal son aquí raros pero muy violentos, como el de Huamancharpa, en enero de 1982, que represó el riachuelo Huancaro, al suroeste y muy cerca de la ciudad del Cusco.

Formación Rumicolca: andesitas shoshoníticas del Plio-Pleistoceno derivadas de un vulcanismo central y fisural (Mendívil \& Dávila, 1994). Presentan mayor estabilidad, salvo donde la solidificación rápida de lavas generó termocuplas o hubo algún evento explosivo que indujo cierta susceptibilidad a derrumbes. Aflora en Tongobamba, Tipón, Huacoto y Rumicolca, donde se ubicaron las principales canteras inkas.

10 Formación San Sebastián, y otros depósitos cuaternarios no consolidados (fluvioaluviales, glaciares y lacustres), que muestran tendencia a provocar pequeños deslizamientos rotacionales y flujos de lodo, producto de intensos procesos de erosión que llegan a formar grandes cárcavas en las terrazas fluvio-lacustres situadas al norte y sur de la cuenca. La presencia de lentes de arena no confinada contribuye a la fuerte inestabilidad de estos materiales.

11 La mayoría de centros arqueológicos estudiados de la cuenca se ubican sobre afloramientos del grupo Yuncaypata, unos pocos sobre los volcánicos Rumicolca y sólo uno en el grupo San Jerónimo. Las construcciones precolombinas emplazadas sobre las terrazas fluvio-lacustres del Cuaternario (sin contar las del centro histórico, donde persisten) prácticamente han desaparecido por enterramiento, vandalismo o uso como canteras. Todas ellas se ubican en el área rural, aunque ya se nota el avance de la urbanización sobre buena parte de ellos, lo cual, sin duda, como ya ha ocurrido con otras zonas, agravará la depredación y los procesos de inestabilidad.

12 Los conjuntos examinados pertenecen, en su gran mayoría, a la cultura Inka (salvo Sillkinchani y Pikillaqta, que son Killke-Inka y Wari-Chanka, respectivamente) y se sitúan en las provincias de Cusco y Quispicanchis, departamento del Cusco. 


\section{Naturaleza y tipología de los fenómenos amenazantes}

13 Aun cuando la amenaza sísmica es la más importante en esta región, el análisis de daños en los terremotos del siglo XX muestra que las construcciones prehispánicas han sido muy poco afectadas por esta causa. Los sismos solo parecen actuar, y de manera restringida, como uno de los eventuales factores desencadenantes de derrumbes y raros casos de deslizamiento rápido que siempre se han dado en lugares ya afectados por fenómenos de inestabilidad pre-existentes, o en fase de latencia o subactividad, es decir, con tasas de movimiento del orden de milímetros a pocos centímetros por año. Incluso en estas circunstancias, la incidencia de las sacudidas sísmicas sobre derrumbes y deslizamientos no ha sido muy relevante, pues, aun en el caso de los derrumbes en la huaca Mosoqllaqta, durante el terremoto de 1986, fue la intervención antrópica (corte del talud interno de una carretera) la causa real de la caída de rocas. superficie menor al kilómetro cuadrado, de carácter lento, algunos en proceso de aceleración, debido a la erosión fluvial lateral y a la socavación en quebradas estrechas (Saphy-Chakán, Salineras, Tipón-Choquepata), a cortes artificiales recientes para habilitar canales o carreteras (Tipón, Mosoqllaqta), o al avance de procesos de karstificación (Tambumachay, Pukapukara, Choquekiraopujyo). Se estima que las velocidades promedio de estos deslizamientos rara vez sobrepasan los $5 \mathrm{~cm} /$ año en algunos puntos, salvo casos particulares que, al ser sometidos a auscultación instrumental, arrojaron velocidades de hasta $4 \mathrm{~cm} /$ mes en deslizamientos de Saphy y Cebollahuaycco, y un caso excepcional, con movimientos de casi $140-150 \mathrm{~cm} / \mathrm{mes}$ durante El Niño 1997-1998, para un deslizamiento muy activo de la margen derecha de Saphy. Estos datos cuantitativos fueron obtenidos por campañas de control geodésico realizadas por el PROEPTI entre 1995 y 1998 (PROEPTI-EPFL, 1999).

Derrumbe: la caída brusca de bloques o masas rocosas se da básicamente en afloramientos alterados de calizas del Yuncaypata, en volcánicos de la formación Rumicolca y en afloramientos del stock diorítico de Saqsayhuaman, en las quebradas de Chakán y Choquechaka.

17 Huayco o lava torrencial: este fenómeno está relacionado fundamentalmente a procesos de represamiento-desembalse generados por el avance de deslizamientos. Son raros en la zona, pero las evidencias sedimentarias muestran que se han producido repetidas veces en el pasado, sobre todo en las quebradas de Saphy-Chakán, Kachimayo y Choquepata.

18 Karstificación: prácticamente el íntegro del llamado Parque arqueológico de Saqsayhuaman se ubica en terrenos del grupo Yuncaypata, sobre afloramientos calcáreos afectados por poinçonnement o Spread y procesos de disolución, que han formado dolinas, cavernas y otras geoformas kársticas.

19 Erosión: los peligros derivados del desarrollo de cárcavas en formaciones cuaternarias representan un importante elemento desestabilizador en algunos conjuntos arqueológicos. Además del peligro que entraña su crecimiento lateral y longitudinal, las cárcavas contribuyen a activar o acelerar deslizamientos y frentes de derrumbe.

Bulletin de l'Institut français d'études andines, 34 (1) | 2005 
Aunque se mencionan los fenómenos de Spread o poinçonnement (separación y deriva de bloques rígidos sobre un substrato blando y plástico) y Topple, no se hace una evaluación específica de ellos, por ser agentes genéticos que conducen, casi siempre, a deslizamientos y derrumbes, por lo que están asimilados a éstos. Solo en casos excepcionales se ha detectado que el Spread continúa, pero a ritmos muy lentos, por lo que sus niveles de peligro inducido son bajos.

Para nuestro análisis, los conjuntos arqueológicos están agrupados por su ubicación geológica y los fenómenos actuantes: construcciones en ladera (l) y en meseta o fondo de valle (f), edificaciones en afloramientos del grupo Yuncaypata (Y), del grupo San Jerónimo (SJ) o de la formación Rumicolca (R).

Cuadro 1 - Tipos de fenómenos peligrosos que amenazan algunos grupos arqueológicos del valle del Huatanay

\begin{tabular}{|c|c|c|c|c|c|c|c|}
\hline $\begin{array}{l}\text { Conjunto } \\
\text { arqueológico }\end{array}$ & $\begin{array}{l}\text { Ubicación } \\
\text { geológica }\end{array}$ & Deslizamiento & Derrumbe & $\begin{array}{l}\text { Colapso } \\
\text { kárstico }\end{array}$ & Huayco & $\begin{array}{l}\text { Spread- } \\
\text { Topple }\end{array}$ & Erosión \\
\hline Saqsayhuaman & $f-Y$ & $\square$ & $\Delta$ & $\Delta$ & $\Delta$ & $\Delta$ & $\Delta$ \\
\hline Chakán & $1-Y$ & $\square$ & $\square$ & $\Delta$ & $\square$ & $\Delta$ & $\square$ \\
\hline K'enqo & $f-Y$ & & & $\Delta$ & & $\square$ & $\Delta$ \\
\hline Pukapukara & $1-Y$ & 0 & $\Delta$ & $\Delta$ & & $\square$ & \\
\hline Tambumachay & $1-Y$ & 口 & 口 & $\Delta$ & 0 & $\Delta$ & \\
\hline Mosoqlllaqta & $1-Y$ & $\Delta$ & 口 & & & & \\
\hline Choquekirao & $1-Y$ & $\square$ & 0 & $\Delta$ & $\Delta$ & $\Delta$ & $\square$ \\
\hline Sillkinchani & $1-S J$ & 0 & 0 & & & & $\square$ \\
\hline Tipón & $1-Y / R$ & $\square$ & $\square$ & 0 & & & 0 \\
\hline Urpikancha & $1-\mathrm{R}$ & $\mathbf{a}$ & 0 & & & & \\
\hline Pikillaqta & $f-Y$ & $\Delta$ & & 0 & & & $\square$ \\
\hline Rumicolca & $f-Y / R$ & a & $\Delta$ & 0 & & & $\Delta$ \\
\hline
\end{tabular}

Amenaza principal;

amenaza secundaria;

amenaza potencial

\section{1. Saqsayhuaman}

Saqsayhuaman ha sufrido mayor destrucción por acción humana que geológica. Fue parcialmente enterrada por orden de Gonzalo Pizarro tras la rebelión de Manco Inka, para no ser empleado en nuevas sublevaciones. Luego, y hasta 1930, fue declarada y usada como cantera pública, por lo que muchos monolitos fueron destruidos a dinamitazos (Pardo et al., 1972). Sobre su naturaleza y funciones persiste un amplio 
debate. Los cronistas lo describen como fortaleza, pero dan también indicaciones sobre sus fines religiosos. Pardo (1957) piensa que pudo ser el Cusco primitivo, un pueblo completo de carácter religioso y militar. Hoy se habla de un templo del sol.

La totalidad del parque arqueológico de Saqsayhuaman, que consta de decenas de sitios al norte de la ciudad del Cusco, se sitúa sobre afloramientos del grupo Yuncaypata y del stock de diorita augítica del Rodadero. Sobre niveles de evaporitas, lutitas y algunas areniscas, se encuentran bloques dispersos de caliza como producto del Spread o poinçonnement. Además de este fenómeno, existen pequeños deslizamientos en varias quebradas secundarias de la cuenca de Choquechaka, y varios frentes de derrumbe, especialmente en los afloramientos del stock diorítico (fig. 2). Igualmente se nota karstificación y relieves ruiniformes. Con referencia a la karstificación subterránea, no hay evidencias ni noticia de colapsos recientes (como los que ocurren con más frecuencia en la meseta de Chinchero), pero, aún así, es prudente pensar en detalladas auscultaciones instrumentales de estos procesos.

Figura 2 - Esquema geodinámico del parque arqueológico de Saqsayhuaman

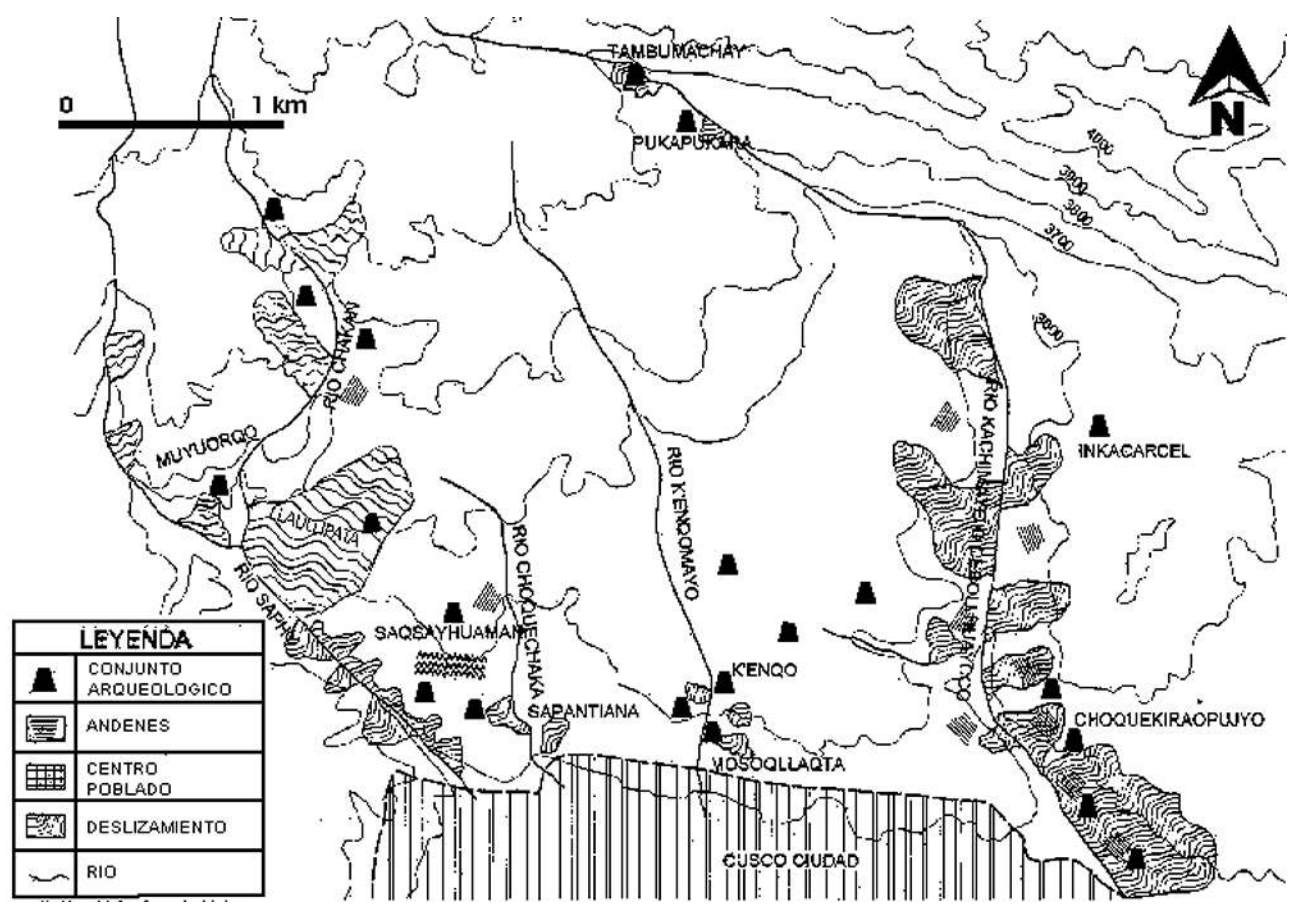

A pesar de que la falla sismogénica activa de Tambumachay se ubica en el parque arqueológico (el conjunto del mismo nombre se sitúa a pocos metros de la línea de falla), los sismos no han causado daño significativo a las construcciones inkas.

Se ha podido determinar, para todo el Parque Arqueológico de Saqsayhuaman, dos grupos genéticos: los derivados de la acción kárstica y las inestabilidades inducidas por la erosión fluvial y glaciar. Esta última actuó en las fases iniciales de excavación de las quebradas, durante la última glaciación pleistocénica (Carreño, 1998b).

La parte principal del conjunto arqueológico, localizada sobre la meseta de Chukipampa, no presenta mayor riesgo, aparte del remoto peligro derivado de los lentos procesos kársticos. Al parecer los trabajos de drenaje emprendidos por los Inkas han reducido en gran medida la infiltración profunda y, en consecuencia, la disolución de sulfatos y carbonatos. La abundancia de terra rossa reduce el potencial de infiltración 
y pone en evidencia que la disolución afecta sobre todo a la caliza y muy poco al substrato de rocas blandas, con lo cual el peligro kárstico se reduce aún más.

Se han identificado frentes de derrumbe en el stock diorítico que aflora en la quebrada de Choquechaka (entrada al parque), en Sapantiana y, hacia la quebrada de Saphy. La mayoría de estas zonas inestables se dan en afloramientos tectonizados y que han sufrido cortes artificiales (Carreño, 1997a).

La quebrada de Saphy está afectada en más de $60 \%$ de sus laderas intermedias del tramo inferior por deslizamientos muy activos. Como ejemplo citamos uno de la margen derecha, cerca al actual campamento municipal, que mostró movimientos de hasta 140-150 cm/mes entre diciembre 1997 y febrero 1998; otros puntos tuvieron promedios de 1-4 cm/año entre 1996 y 1999 (PROEPTI-EPFL, 1999). Esta alta incidencia de deslizamientos explica, junto al uso como canteras, la desaparición de la mayor parte de los trabajos de canalización, andenes y otras construcciones inkas en la cuenca inferior del Saphy. Las pérdidas y deterioro de patrimonio inka derivados de la acción geodinámica involucran diques, canales, andenes, drenajes subterráneos y superficiales, puestos de control y caminos. Resulta claro que además de la acción geodinámica, han contribuido a este hecho, acciones de depredación como secuela del huaqueo, vandalismo, explotación de canteras, urbanización, ampliación de la frontera agrícola, etc. (Carreño, 1997b).

La actividad de varios de estos deslizamientos se ha agravado en los últimos años, por la destrucción de los sistemas de drenaje inkas, por la construcción del llamado campamento municipal y por una serie de obras de canalización y de supuesta estabilización mediante técnicas inadecuadas. Durante las temporadas de lluvia del 2002 y 2003 se han producido numerosos pequeños deslizamientos rápidos y flujos, que han llegado a formar represamientos restringidos, generando una evidente aceleración de bloques inestables mayores, cuyas cabeceras se acercan a la zona de los torreones. Dos de estos episodios se dieron en la zona de transición meseta-valle del riachuelo Choquechaka (garganta de Sapantiana), uno de los cuales destruyó más de cincuenta metros de la plataforma del camino de entrada al parque arqueológico, represando el curso de agua (fig. 3). 
Figura 3 - Deslizamiento en el stock diorítico de Rodadero, al pie de la zona de torreones de Saqsayhuaman (quebrada de Choquechaka)

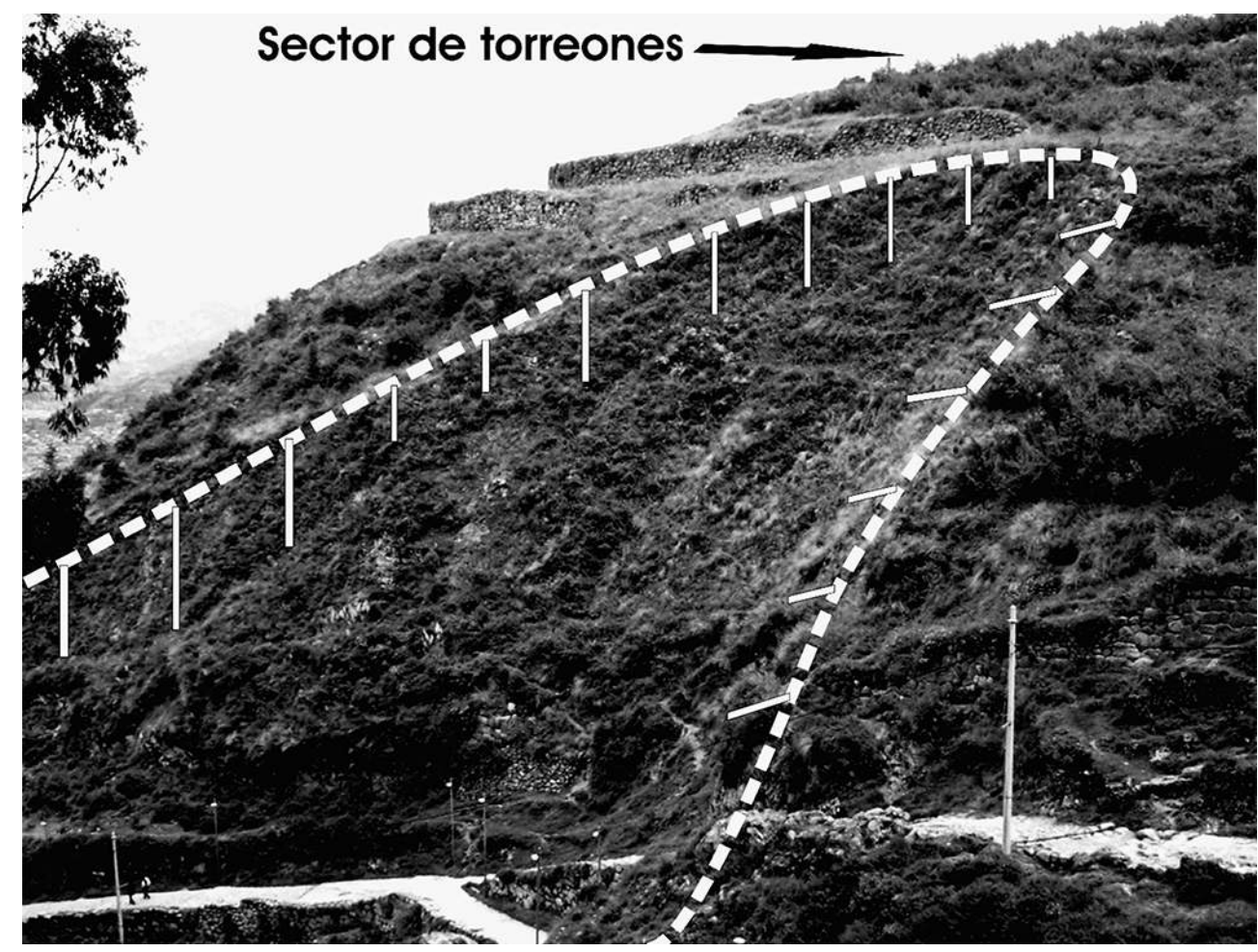

En marzo de 2003, la parte inferior sufrió un episodio de aceleración que destruyó parte del camino de acceso y muros.

30 Hacia el norte existen varios deslizamientos rocosos, como el de Llaullipata, con un área superior al kilómetro cuadrado, ya descrito por Fleming et al. (1986), subestabilizado en su mayor parte, pero en cuyo pie existen varios deslizamientos secundarios bastante activos.

31 Estos mismos autores señalan que la habilitación de canteras de caliza influyó en la reactivación de varios deslizamientos. Hoy esas canteras están abandonadas pero, al no existir planes de cierre de mina, los frentes de inestabilidad permanecen activos, provocando flujos, hundimientos y derrumbes que, en varios puntos, interrumpen las carreteras del circuito turístico o afectan restos inkas.

En términos generales, los niveles de peligrosidad en Saqsayhuaman son bajos, a excepción de la quebrada de Saphy. Los problemas asociados de erosión y los pequeños deslizamientos existentes en las cabeceras de la quebrada de Choquechaka, donde hay restos arqueológicos de segunda importancia, parecen fácilmente manejables. Solo el promontorio donde se ubican los torreones podría, en el largo plazo, sufrir el efecto de la regresión de los deslizamientos activos de Saphy.

\section{2. Chakán}

En la quebrada de Chakán existe un interesante sistema hidráulico que consta incluso de una represa y varios diques de derivación y de control de crecidas, así como de una serie de canalizaciones y andenes destruidos o muy deteriorados por acción humana y por deslizamientos, erosión y huaycos. 
34 en su tramo inferior, próximo a su confluencia con la quebrada de Saphy, donde las dioritas alteradas, los materiales morrénicos, las evaporitas y sedimentos aluviales, geodinámicamente muy sensibles, fueron tratados mediante andenes, cortes y rellenos compensatorios, drenajes y canalizaciones, obras inkas que, al ser abandonadas o depredadas, han perdido su capacidad de estabilización y de control de la erosión, al punto que ésta ha profundizado el cauce del riachuelo hasta más de cuatro metros, como lo indican algunos restos de la antigua canalización hoy «colgados» a esa altura. La erosión se da a tal ritmo (con una grave secuela de deslizamientos y flujos de detritos) que la morfología del canal cambia anualmente. Cascadas de más de tres metros, que existían hace unos veinte años, hoy han desaparecido. Todo esto viene contribuyendo a acelerar grandes deslizamientos, algunos de los cuales amenazan con degenerar en episodios paroxísticos que represarían la quebrada.

Angles (1988) da noticia de un aluvión que hace algunos decenios arrasó algunos restos, afectando parte de lo que él llama el intiwatana de Llaullipata. Este aluvión debió, sin duda, corresponder a uno de los frecuentes fenómenos de represamiento y desembalse (en su mayoría de poca monta) que se producen en esta cuenca, como efecto del avance de los muchos deslizamientos activos.

36 En el cerro Muyuorcco, que marca la confluencia entre los riachuelos Chakán y Saphy (fig. 4), dos deslizamientos muy rápidos (siendo el de su flanco occidental el más activo, habiéndose medido desplazamientos verticales de más de diez metros en cinco años) vienen destruyendo irremediablemente los restos de lo que Bauer (2000) piensa que fue una huaca (la séptima del sexto ceque del Chinchaysuyo).

Figura 4 - Cuenca de Saphy-Chakán

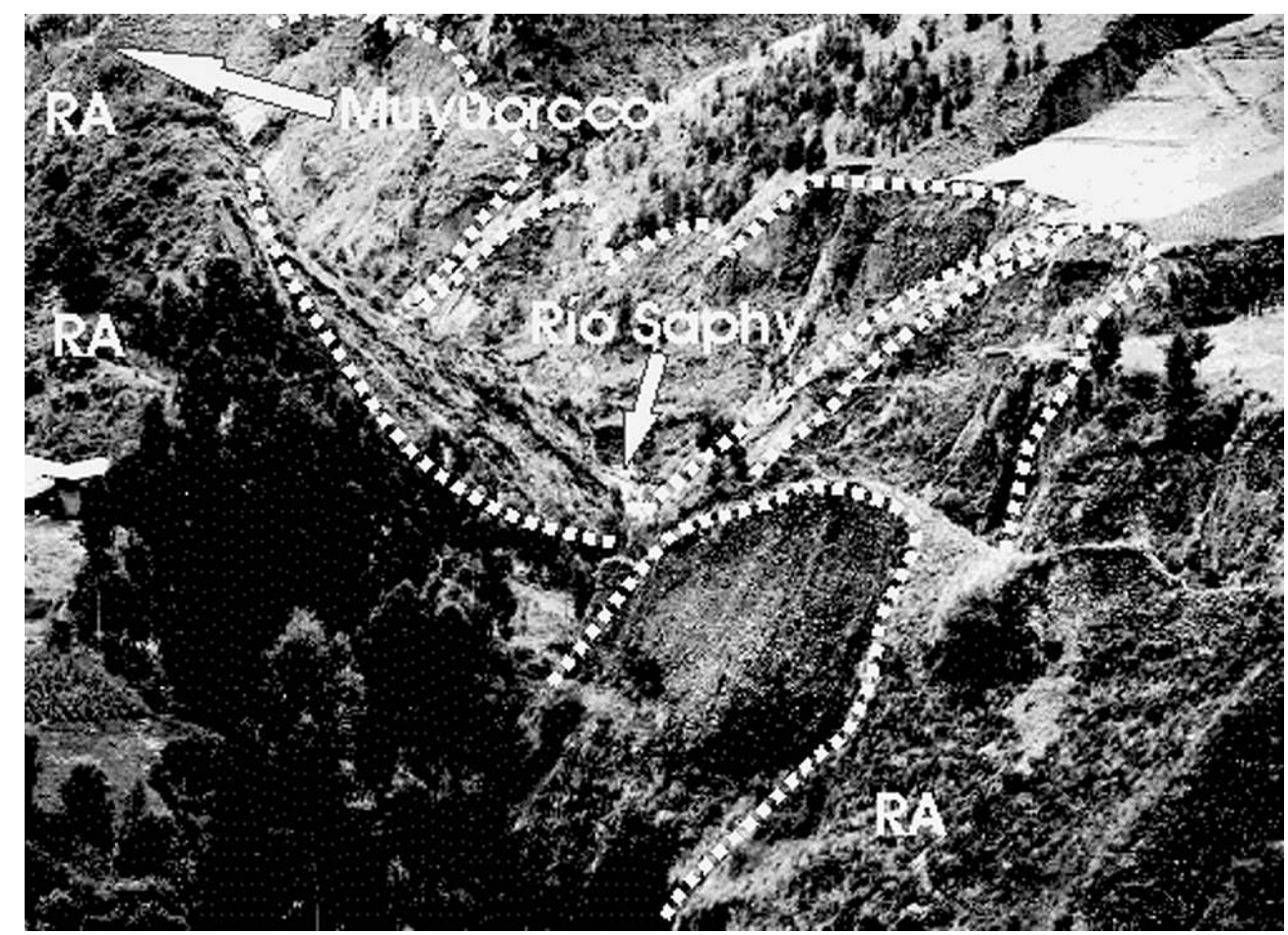

Erosión y deslizamientos muy activos (línea punteada) en el cerro Muyuorcco y sus alrededores, con restos arqueológicos (RA) parcialmente destruidos

Bulletin de l'Institut français d'études andines, 34 (1) | 2005 


\section{3. K'enqo} repositorios arqueológicos, K'enqo es considerado como observatorio astronómico y sitio de cultos diversos y aun de sacrificios (Angles, 1988). Este autor también señala que la mayor parte de construcciones fueron destruidas, quedando solo bases de muros y los asientos sobre los afloramientos de caliza.

38 Grande radica no tanto en las escasas construcciones que restan sino en las esculturas y molduras que se hicieron sobre los bloques calcáreos. K'enqo chico presenta solo restos de un muro de contorno y bases de construcciones menores. Ambos están construidos sobre bloques de caliza movilizados por fenómenos de spread o poinçonnement, sometidos a karstificación. Los bloques calcáreos tienden a separarse al «flotar» sobre lutitas y arcillas. El relieve ruiniforme, los lapiaces y otras formas de disolución fueron aprovechados por los inkas para hacer tallados e incisiones tal vez más con afán lúdico que utilitario o ceremonial.

39 En el plano geodinámico, la erosión y una probable reactivación del Spread son las amenazas que se ciernen sobre este sitio. En los cuatro últimos años, varios pequeños deslizamientos-flujo inducen la formación de cárcavas en la base de los grupos arqueológicos, lo cual podría, en un futuro próximo, acelerar la separación de bloques. Para contrarrestar esto se hace necesario controlar el drenaje y proteger el pie de los afloramientos calcáreos.

Dentro de la llamada galería donde se ubican una hornacina y una suerte de ara -y que no es una cueva excavada como algunos sugieren, sino la grieta de separación de la caliza-, se nota claramente la importancia del fenómeno de deriva de bloques. Un análisis de fisuras en el techo de este pasaje de orientación este-oeste prueba que ha habido poco movimiento desde tiempos del Inkario; en cambio, un juego de fisuras de dirección aproximada NE-SO sí muestra signos de separación más reciente, con luces de hasta tres centímetros; esto se prueba por la naturaleza y estado de las fisuras y de sus bordes y por el tipo de karstificación que cubre sus paredes. La desaparición de paramentos, que normalmente cierran las grandes grietas, podría también deberse a la separación de bloques. En cualquier caso, el ritmo de avance de la deriva de bloques (fig. 5a) es muy lento y no representa, por el momento, mayor peligro para esta zona.

Bulletin de l'Institut français d'études andines, 34 (1) | 2005 


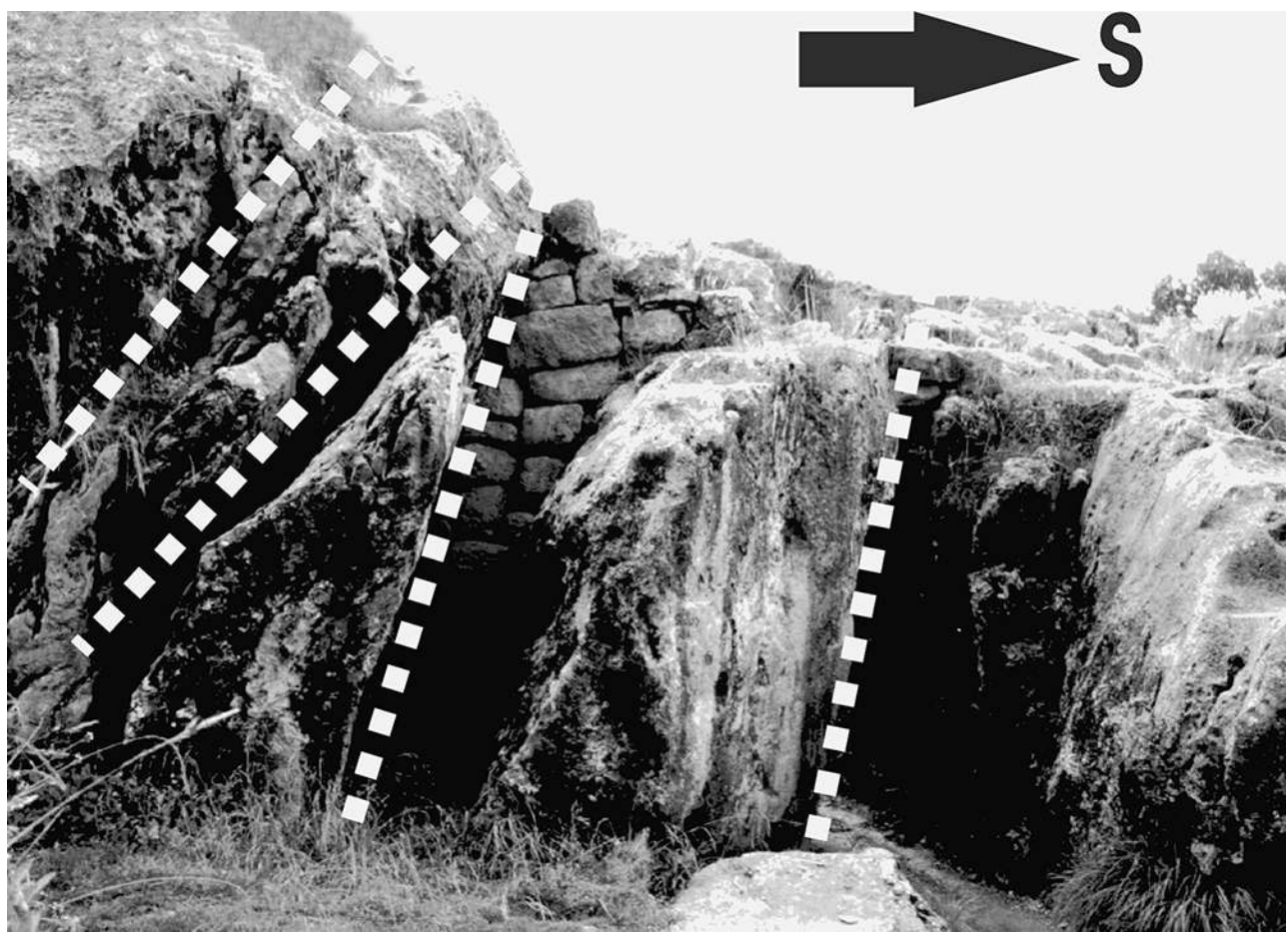

Las líneas entrecortadas señalan la separación de bloques; la flecha, la dirección de la deriva de bloques hacia el sur

41 K'enqo Chico está afectado por procesos menores de erosión al pie de su borde nororiental. La excavación en forma de zanja que se hizo para desenterrar y hacer visibles los restos de muros en esta parte ha contribuido a desarrollar un pequeño deslizamiento en el glacis situado inmediatamente al norte. Las deformaciones del suelo son importantes y se nota que éste y el recientemente formado deslizamiento vecino a K'enqo Grande están en proceso de unirse, lo cual implicaría la pérdida de soporte lateral de los bloques calcáreos, con fuerte potencial de reactivación del Spread.

Con relación a este último deslizamiento, que involucra material sedimentario resultante de la descomposición de las calizas, su desarrollo toma un cariz inquietante, pues está situado sobre la margen derecha del riachuelo K'enqomayo, frente y al pie de K'enqo Grande. En los últimos siete años, este deslizamiento ha formado escarpas con rechazos verticales de un metro en promedio (fig. $5 b$ ), afectando incluso parte de la plataforma de la carretera turística. Existen, en la actualidad, numerosas grietas activas con aberturas superiores a los diez centímetros. Una obra de tratamiento del cauce del K'enqomayo (disipadores escalonados de gaviones) parece haber agravado este deslizamiento. Se trata, a todas luces, de una obra inadecuada para las condiciones morfológicas e hidráulicas del sitio. Además de ello, el último disipador ha desviado la corriente fuera de su cauce original, formando una amplia cárcava que socava el pie de la peña de K'enqo Grande, lo que, sin duda, reactivará, como en el caso anterior, el Spread. 
Figura 5b - K'enqo Grande

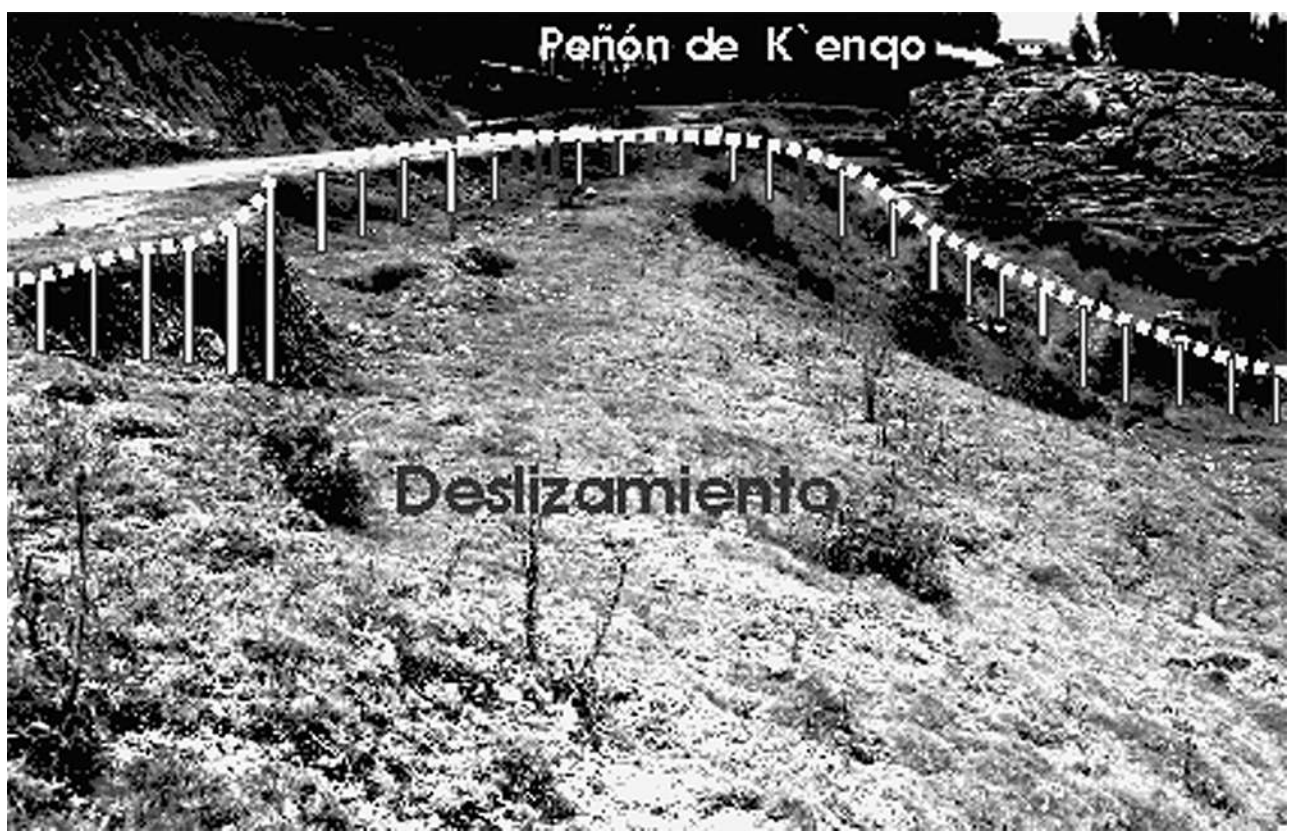

Vista parcial del deslizamiento (línea punteada: corona y escarpa) que desvía el riachuelo K'enqomayo, el mismo que viene erosionando la base del peñón

43 En otra perspectiva, dos factores muy importantes de deterioro y destrucción de origen antrópico corresponden, primero, al tránsito de turistas y animales sobre los bloques tallados (lo que acelera su desgaste; en los últimos años, muchas de las superficies lucen muy pulidas y varias figuras han comenzado a borrarse) y, segundo, a la realización de ceremonias místicas, muy de boga en estos tiempos, en los llamados altares situados dentro de las cavernas, donde el uso de fogatas, velas y hachones comienza a transformar la caliza en cal. Estas dos prácticas deberían ser erradicadas para preservar el monumento, toda vez que, a diferencia de otras edificaciones con paramentos cuyos sillares pueden ser substituidos, las esculturas sobre estos afloramientos rocosos son irreemplazables. Estas agresiones, casi tanto como los fenómenos geodinámicos, constituyen la mayor amenaza inmediata sobre K'enqo.

\section{4. Pukapukara}

Para Zecenarro (2001) es la séptima huaca del segundo ceque del Antisuyo, denominada Kaynakunka. Bauer (2000) plantea que sería la novena huaca del primer ceque del Antisuyo, llamada Tampumachay. Angles (1990) señala que Pukapukara es un nombre puesto en el siglo XX. Al parecer, el sitio de Pukapukara se llamó Tampumachay, mientras que el sitio que hoy tiene ese nombre correspondería a T’impuqpujyo. Por su ubicación y disposición arquitectónica, resulta evidente que la función primordial de Pukapukara fue, ante todo, militar, como ya lo infiere Pardo (1957), al decir que desde su posición dominante se controlaban los caminos que venían de Calca y Urubamba, al mismo tiempo que permitía velar por la seguridad de la familia real durante sus visitas al balneario de Tambumachay.

Como K’enqo, pero en una posición de desnivel más pronunciado, este conjunto está edificado sobre un bloque calcáreo movilizado por acción del poinçonnement. Es probable que también haya sufrido algo de transporte glaciar, durante la última 
glaciación pleistocénica. El problema aquí está relacionado a un típico mecanismo de Spread, o deriva de bloques, seguido de Topple rígido, o basculamiento del bloque calcáreo dentro de una masa plástica subyacente (fig.6), que luego degenera en procesos combinados de derrumbe y deslizamiento. Ya se nota la separación de algunos bloques diaclasados. Esto, sumado a la compactación derivada del creciente tránsito humano y animal y la sofusión, procesos que alteran el drenaje, ha comenzado a producir agrietamientos y desplome de muros, algunos de los cuales, reacomodados hace pocos años, muestran nuevamente pandeos, inclinaciones y desacomodo de bloques, lo que ha sido disimulado con barro en los intersticios.

Figura 6 - Esquema del proceso de Spread (deriva) y Toppling (basculamiento) en Pukapukara

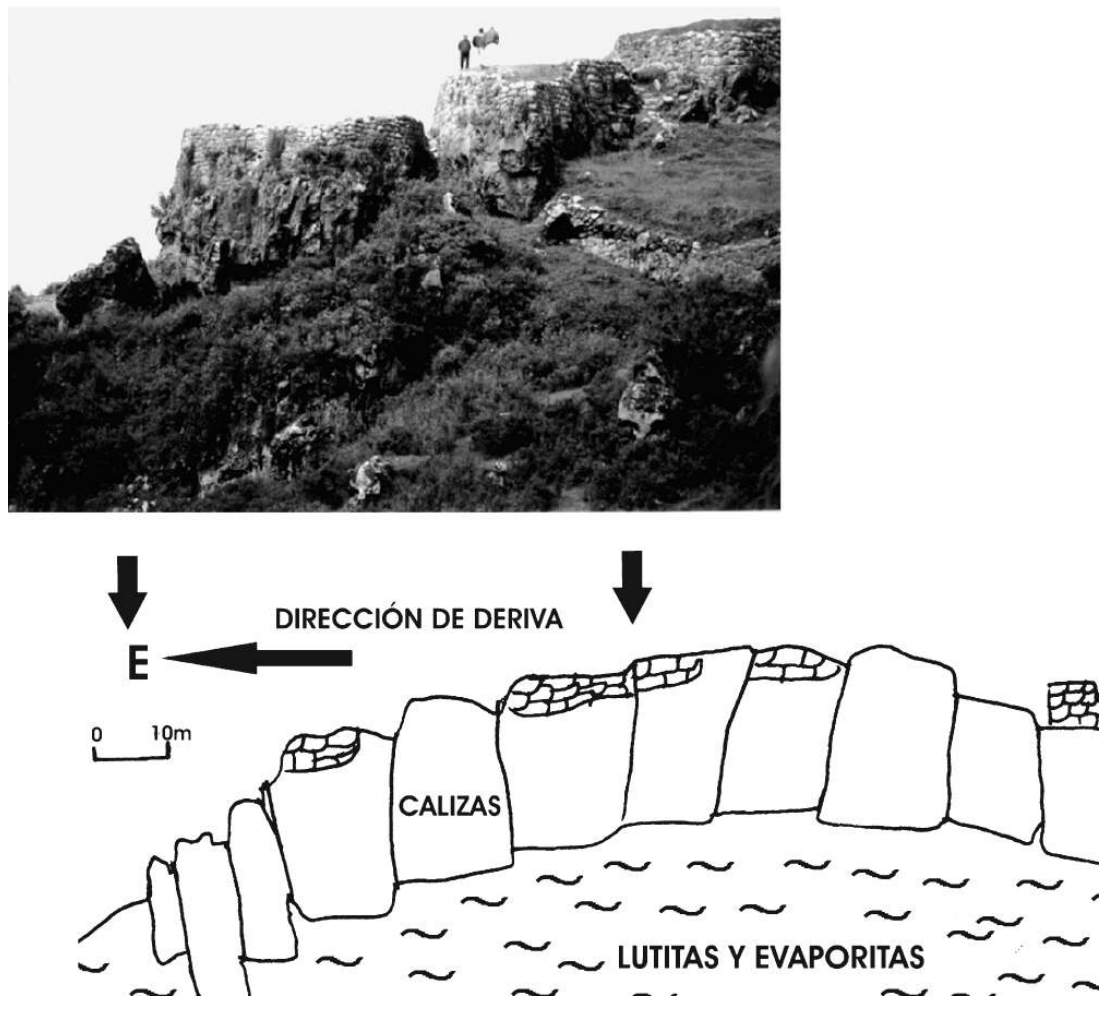

En la foto, detalle de bloques calcáreos escalonados, hundidos por efecto del poinçonnement. La flecha horizontal señala la dirección de deriva, hacia el oriente

Pardo informaba, hace casi cinco décadas, que los muros adosados a las rocas estaban bastante deteriorados. Esto podría interpretarse justamente como efecto de la separación de los bloques calcáreos, uno de los cuales se derrumbó. Por el estado del material, podría deducirse que el derrumbe fue relativamente reciente.

Un problema que comienza a tomar importancia es el de la intensa socavación de riberas que provoca el riachuelo Tambumachay o Kachimayo, de fuerte régimen torrencial y que, al pie del promontorio de Pukapukara, adquiere mayor gradiente y capacidad de erosión. El mismo Pardo (1957) lo describía como «un pequeño riachuelo, que en invierno escatima sus aguas, y en la época lluviosa, es torrente incontenible, que arrastra peñascos [...]», lo que da una idea de su potencial erosivo. Su canalización ha desaparecido y los pocos restos que quedan de ella están siendo actualmente barridos por una serie de deslizamientos ribereños que van generando cárcavas regresivas en ambas márgenes. En la parte oriental se vienen desarrollando cárcavas al pie del 
afloramiento calcáreo. Es hacia ese lado que los bloques se vienen separando e inclinando por efecto del Toppling. Unos 200 metros más al este, una serie de trabajos de conservación de suelos (zanjas de infiltración y terrazas en zonas inestables) han inducido efectos contraproducentes en corto tiempo, generando des-lizamientos, fuerte erosión y flujos de lodo que, en el futuro, podrían alcanzar y desestabilizar aún más la base del conjunto arqueológico.

\section{5. Tambumachay}

Muchos de los historiadores y arqueólogos que interpretan al cronista Polo de Ondegardo afirman que se trata de la octava huaca del primer ceque (Qollana, el principal de todos) del Cusco y propiedad de Inka Yupanqui. Bauer (2000), plantea que sería Quinoapuquio, la décima huaca del primer ceque del Antisuyo. La mayoría de autores coinciden en señalar que era un lugar de culto al agua y un balneario de la realeza inka. Tambumachay consta de un núcleo principal (sobre la margen derecha del riachuelo K'allachaka-Kachimayo, donde está la fontana, o «Baño de la Ñusta», y el llamado «lienzo pétreo»), grandes andenes hacia el este, una posible pequeña fortaleza hacia el suroeste, y una especie de torreón cuadrangular al frente, sobre la orilla opuesta del riachuelo.

49 A pesar de estar en una zona donde abundan los afloramientos calcáreos, la parte principal de este conjunto arqueológico ha sido edificada sobre rellenos y aluviones que contienen material coluvial sobre un glacis de suave inclinación. Los restos están amenazados por derrumbes y pequeños deslizamientos poco profundos que (fig. 7), sin embargo, han comenzado a causar desarreglos en los conductos subterráneos del agua que llega a la ya mencionada fuente.

Figura 7 - Tambumachay

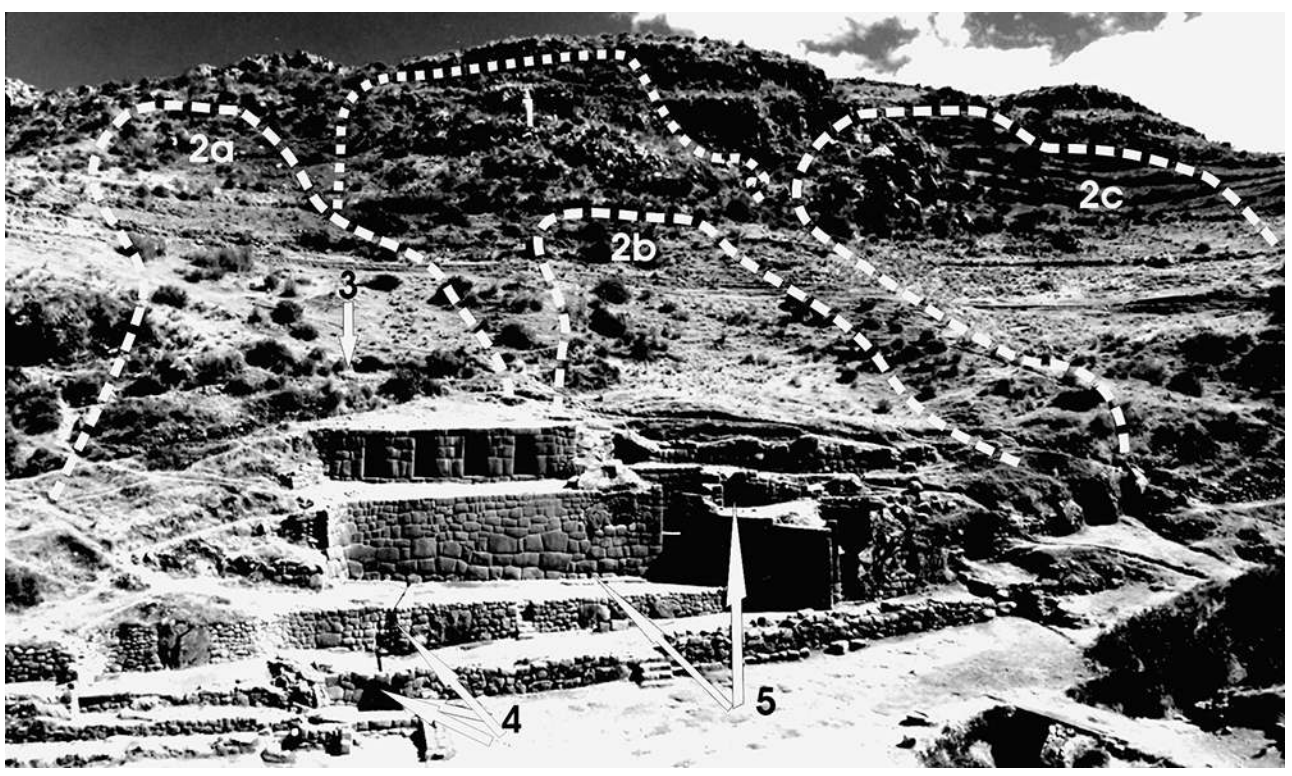

1: calizas fracturadas (frente de derrumbes y deslizamiento en formación); 2a, b, c: deslizamientos; 3 : canal de riego; 4: fuentes; 5: puntos de filtración de acueductos subterráneos

En la parte alta, hacia el sur, un acantilado de calizas muy fracturadas representa la mayor amenaza sobre el conjunto arqueológico y sus visitantes. Son numerosas las 
evidencias de derrumbes más o menos continuos que llegaron hasta las cercanías del núcleo arqueológico.

Detrás del edificio principal y del paramento de las fuentes, existen tres pequeños deslizamientos de carácter terroso, cuya profundidad no debe sobrepasar los cuatro a cinco metros, pero que, por la naturaleza del material, pueden formar flujos de lodo. Una foto tomada por Miguel Chani alrededor de 1915 muestra de mejor modo la traza de dos deslizamientos, siendo incluso visible, en el oriental, la escarpa principal. En la actualidad, la superficie de éste ha sido modificada y la traza es apenas perceptible. El tercero, al occidente, parece haberse formado posteriormente. Por su forma, estos pequeños deslizamientos podrían ser resultado de un tipo de asentamiento por disolución. Como se dijo, su actividad habría afectado los canales subterráneos, por lo que, desde hace algunos años, parte del agua se filtra al pie del muro principal antes de llegar a las fuentes. En la parte superior, al nivel de las hornacinas, las rocas han comenzado a mostrar eflorescencias calcáreas y sulfatadas, producto de la fuga del agua canalizada hacia zonas sin drenaje, disolviendo algunos de sus componentes mineralógicos. Estas eflorescencias eran desconocidas anteriormente, cuando tampoco había fugas de agua por los intersticios de los muros.

La situación se ve agravada por el pastoreo y por la existencia de un canal de riego sin revestimiento que pasa por los deslizamientos y al pie del acantilado calcáreo, justo detrás de la parte principal del centro arqueológico. Las pérdidas de agua por infiltración o desborde de este canal contribuyen a agudizar las condiciones de inestabilidad del sitio.

\section{6. Mosoqllaqta}

Mosoqllaqta es conocida por la gente como una huaca, pero los estudios arqueológicos no la mencionan como tal, salvo que se considere como parte del grupo arqueológico de Mesa Redonda-Cinca, situado más abajo, por donde pasa el camino inka al Antisuyo. Bauer (2000) considera a Mesa Redonda como candidata para ser la segunda huaca del segundo ceque del Antisuyo (Pachatosa).

Este pequeño centro arqueológico, que se ubica cerca de K’enqo, está también, como la mayoría de conjuntos de la zona, construido sobre un bloque de caliza desplazado, alterado y bastante fracturado por efecto del Spread y ha sido destruido en su mayor parte por la extracción de materiales, por la acción de los derrumbes y por el corte de la carretera de circunvalación del Cusco. Al intensificarse el tráfico por esta vía, que lleva a Saqsayhuaman, al Valle Sagrado y a varios asentamientos humanos recientes, las vibraciones provocan la caída casi constante de piedras sobre la carretera. Un pequeño deslizamiento lateral (fig. 8) afectó canales y muros vecinos y fue objeto de trabajos de estabilización, los cuales no han dado resultado, pues la masa continúa en movimiento, afectando lo que queda de un canal inka. 


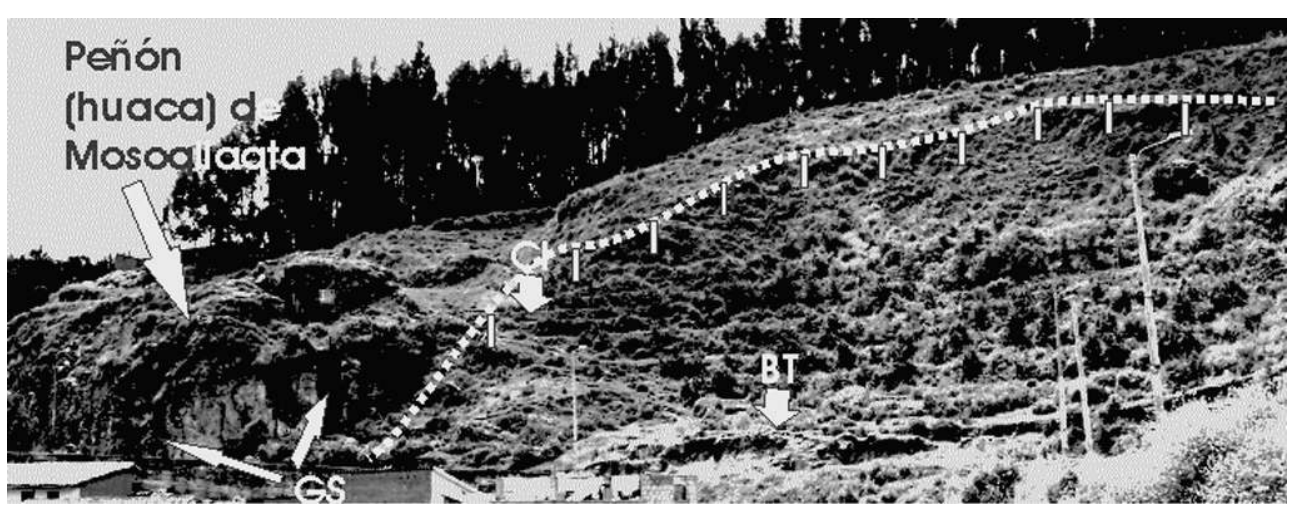

A la izquierda bloque principal: con restos de muros y entalladuras, afectado por un proceso de Spread (GS: grietas de separación) y por derrumbes. BT: bloque calcáreo tallado. Cl: canal inka. Línea punteada, límite y escarpa del deslizamiento activo

Los derrumbes causa-dos por el sismo del 5 de abril de 1986 fueron muy destructores: una masa de unos $80 \mathrm{~m}^{3}$ bloqueó la carretera, enterró dos viviendas y causó dos muertos, llevándose de paso algunos restos de muros inkas.

Aunque queda muy poco de la construcción original (pues a la fecha han desaparecido la mayoría de paramentos de piedra labrada, se han inutilizado los drenes inkas y distorsionado el flujo por una antigua canalización, debido a que los materiales desaparecieron durante la apertura de la citada carretera o fueron saqueados para ser usados en cimentaciones, sobre todo en los años 60 y 70 del siglo pasado), la degradación progresiva del bloque de caliza, por efecto de los derrumbes (y anteriormente por canteras clandestinas), pone en serio peligro los restos de muros y canales que aún subsisten, constituyendo, además, una seria amenaza para transeúntes y vehículos.

\subsection{Kachimayo-Choquekiraopujyo}

57 La quebrada de Kachimayo o Cebollahuaycco, llamada también Salineras o K’allachaka, corta unidades sedimentarias muy incompetentes del grupo Yuncaypata y de la formación San Sebastián al este de la meseta de Saqsayhuaman, lo cual condiciona la fuerte densidad de fenómenos de inestabilidad, en especial, de grandes deslizamientos. Sobre la margen izquierda afloran evaporitas, lutitas y calizas en disposición caótica, con frecuentes relieves ruiniformes.

En esta cuenca se encuentran varios grupos arqueológicos, como Rumihuasi, Inkiltambo, Torrechayoc, Andenniyoc, etc., de los cuales el más importante resulta Choquekiraopujyo. Además de las construcciones con muros de mampostería finamente labrada, existen los conocidos bloques esculpidos de caliza, tan comunes en todo el parque de Saqsayhuaman y que, como indicamos, son producto de la disgregación, deriva y dispersión de bloques calcáreos por efecto del poinçonnement. Bauer (2000) y Zecenarro (2001) coinciden en que este conjunto habría albergado hasta tres huacas del cuarto ceque del Antisuyo: Choquequirao puquio, Callachaca (que correspondería a una de las estructuras cónicas, o sayhuas del conjunto principal) y Viracocha. Destacan en el conjunto dos sayhuas -construcciones en forma de torreón- formadas por andenes cuasi circulares en escalonamiento concéntrico y que formarían parte de una suqanqa, 
estructura que habría servido para la exacta determinación del solsticio y a la que faltarían los dos pequeños gnómones centrales.

Con mayor frecuencia que en los bloques calcáreos de la zona de Saqsayhuaman y K'enqo, los intersticios que separan dos bloques de caliza fueron cerrados con muros de buena factura, como en el llamado «nicho ceremonial». Estos muros, que podríamos llamar intersticiales, según su estado de conservación, sirven como indicadores de la actividad de separación de los bloques calcáreos y prueban que el fenómeno de Spread continúa, aunque en muy pocos casos y a un ritmo muy lento.

De las sayhuas, la llamada Machuchoquekirao se sitúa sobre una estrecha cresta rocosa que separa los dos deslizamientos gigantes de Salineras (fig. 9a), que cubren un área cercana a los $2 \mathrm{~km}^{2}$. El deslizamiento inferior tiene compartimentos muy activos. En los últimos años se nota un evidente proceso de aceleración. La campaña geodésica 1995-1997 del PROEPTI revela movimientos promedio de hasta 2-4 cm/mes; en la temporada lluviosa de 1997-1998, ciertos puntos que tenían promedios de $3 \mathrm{~cm} / \mathrm{mes}$ pasaron a velocidades de $18 \mathrm{~cm} / \mathrm{mes}$ (PROEPTI-EPFL, 1999). La evolución ulterior de algunos deslizamientos secundarios, donde se hicieron las mediciones, ha ratificado la importancia de los movimientos, por cuanto han sufrido aceleraciones críticas que llegaron incluso a represar el río Kachimayo, aunque sin mayores consecuencias, por el volumen restringido de los embalses y por la rápida evacuación fluvial (la pendiente media del río es de $7 \%$, pero alcanza el $18 \%$ al pie del deslizamiento mayor). Varios compartimentos más rápidos han comenzado a destruir andenes y amenazan a parte de la sayhua mayor o Machuchoquekirao. La sayhua menor, Huaynachoquekirao, está construida sobre un bloque calcáreo desplazado por spread en un sector casi inactivo del deslizamiento, lo que reduce su exposición a los efectos del movimiento de masas.

Figura 9a - Choquekiraopujyo

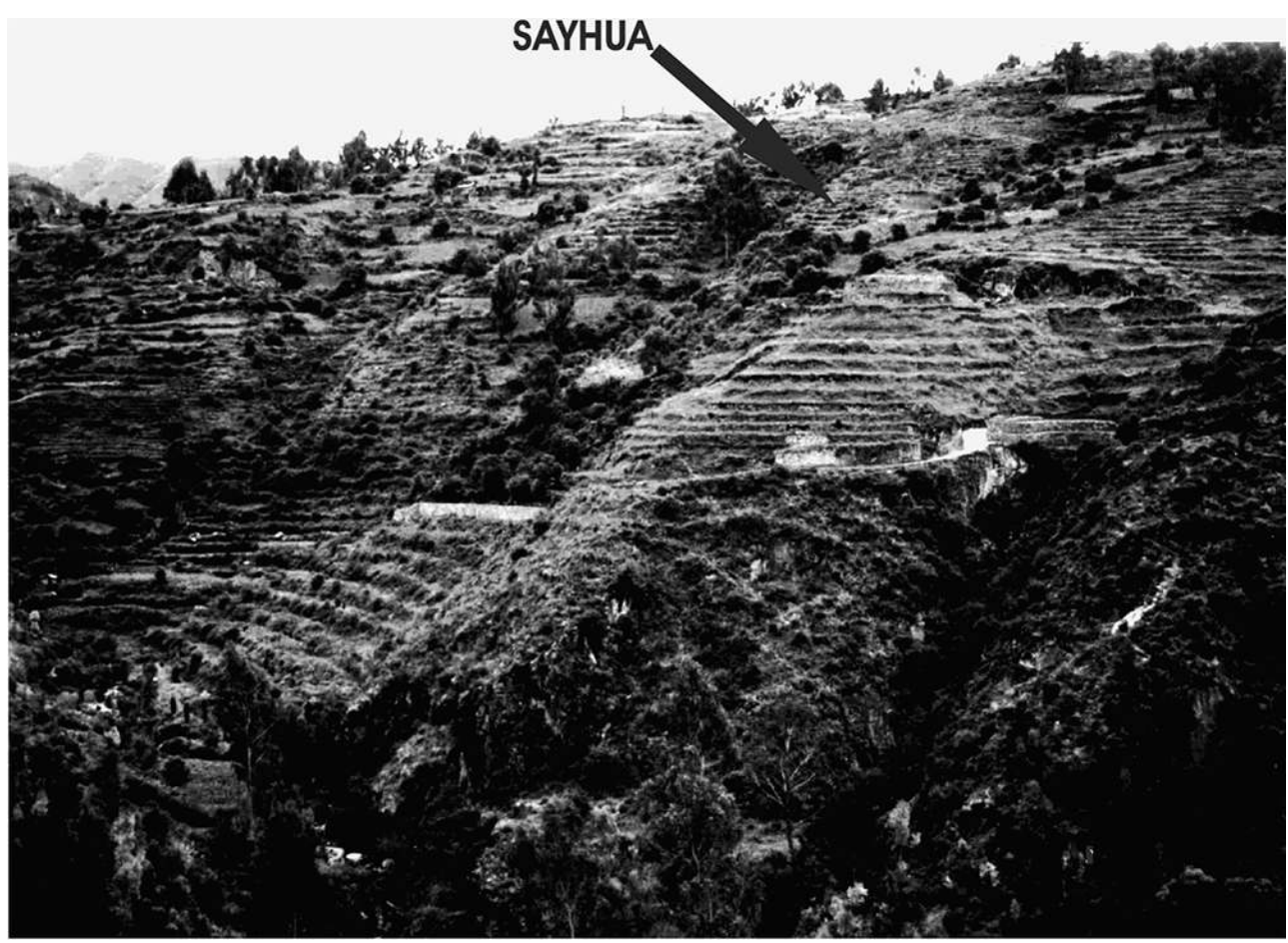

Vista de una de las sayhuas sobre la cresta que separa los dos deslizamientos gigantes de Salineras 
61 El deslizamiento contiguo es un claro ejemplo de la capacidad de identificación y tratamiento de un deslizamiento gigante que desarrollaron los antiguos cusqueños (aunque esto, debemos remarcarlo, no se debe generalizar). Este gran deslizamiento rotacional muy evolucionado, fue íntegramente acondicionado con andenes rectos y curvos y un excelente sistema de drenaje subterráneo y superficial. La erosión de pie fue controlada mediante disipadores escalonados y canalización. El estado de conservación de la andenería demuestra que el tratamiento fue efectivo y solo en los últimos años, por falta de mantenimiento de canales y paramentos, así como por prácticas agrícolas y pastoriles inapropiadas, se nota la reactivación de algunos bloques secundarios con planos de ruptura relativamente superficiales.

62 Al haber desaparecido la canalización del río y por el virtual estado de abandono del canal de riego inka que atraviesa toda la parte central del deslizamiento de Salineras, la erosión en cárcavas y del pie de los taludes se ha acentuado. Hoy en día, varios niveles de andenes, pequeños recintos de habitación situados en la parte inferior de la ladera y gran parte de la antigua canalización han desaparecido por acción del vandalismo y, principalmente, por el empuje del deslizamiento. Al acelerar los bloques inferiores y ser erosionadas rápidamente las masas caídas dentro del cauce fluvial, los frentes de actividad tienden a progresar ladera arriba, involucrando masas cada vez mayores, lo cual podría desembocar en una reactivación y aceleración general de todo o gran parte del deslizamiento gigante, comprometiendo la mayoría de grupos arqueológicos de la zona (fig. 9b). En resumen, este grupo arqueológico es tal vez, junto a algunos restos menores de la quebrada de Chakán, el más amenazado de todos los que han sido analizados hasta la fecha en la cuenca del Huatanay.

Fig. 9b - Andenes y restos de recintos Inka afectados por el mayor deslizamiento activo de Salineras

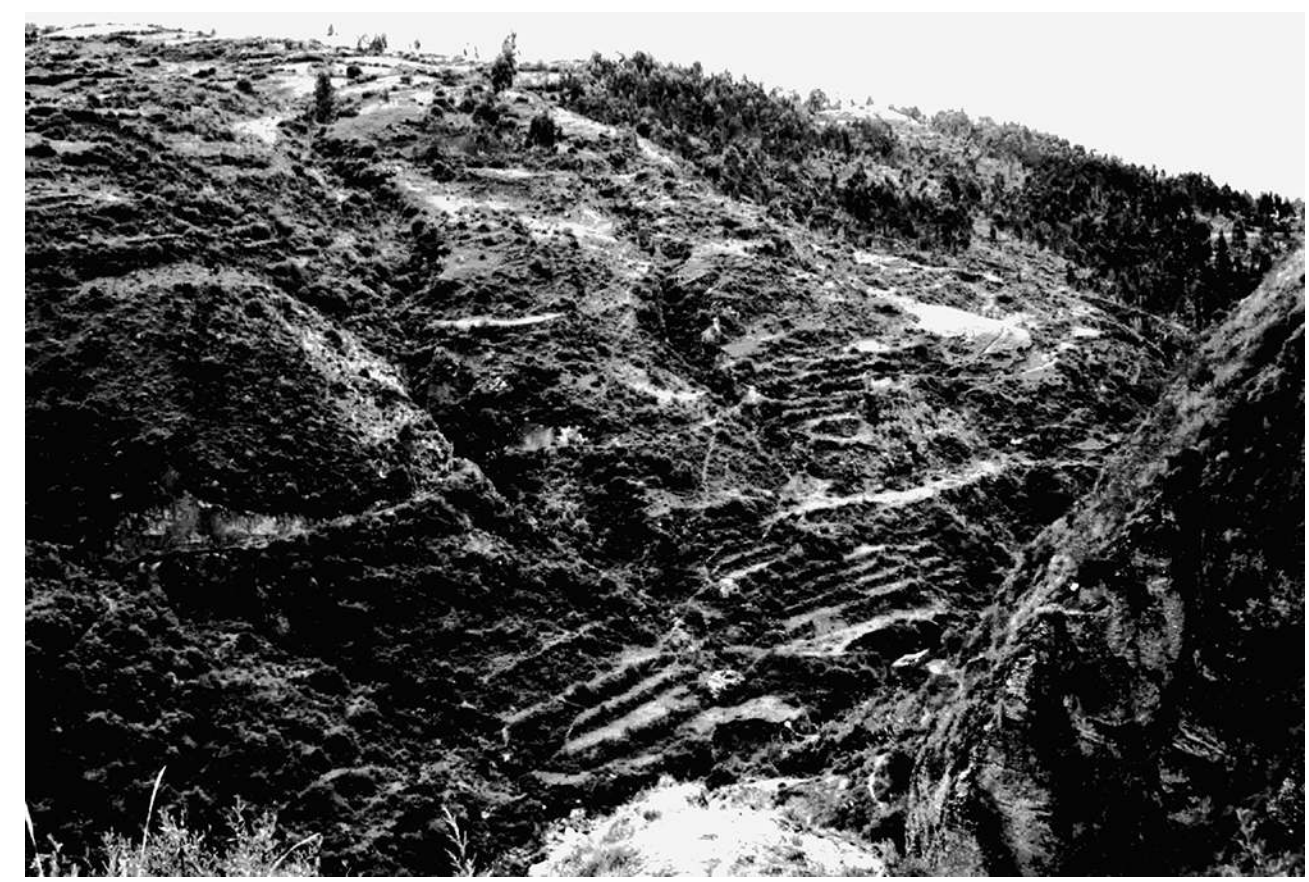




\section{8. Sillkinchani}

63 poniente, sobre afloramientos de capas rojas del grupo San Jerónimo, teniendo al pie y hacia el sur restos de terrazas lacustres y abanicos fluvio-aluviales, afectados por cárcavas y deslizamientos subactivos pequeños.

Sillkinchani habría sido un centro «de interacción relacionada a la producción ganadera, alfarera, agrícola [...] [que] sirvió para acumulación de la producción agrícola» (Cumpa, 2001). Para Huaycochea (1994) se trata de depósitos (qolqas), administrados desde el cercano asentamiento de Tambillo. Se piensa que pudo ser la séptima huaca (Guamansani) o la octava (Guayra) del camino al Qollasuyu, descritas por el cronista Cobo. Por su ubicación en el único y estrecho paso de llanura hacia el Cusco (llamada precisamente Angostura, garganta que señala el límite entre las cubetas de Cusco y de Huacarpay, componentes del desaparecido lago pleistocénico de Morkill), es más probable que haya sido una suerte de posta de vigilancia y control.

Los estudios recientes identifican dos ocupaciones bien definidas: Inka y K'illke (Mormontoy, 1995). Se han reconocido tres subsectores: el I, y mejor conservado, consta de nueve recintos rectangulares tipo ka-llanka ordenados en tres hileras paralelas; el II, descubierto en 1998, al noroeste del anterior, sería una kancha inka; el III, al sur, que consta de terrazas y recintos rectangulares. Al pa-recer existen otros restos aún enterrados. Cumpa (2001) men-ciona que, hace unos veinte años, la empresa encargada de instalar las cercanas torres de alta tensión, al abrir una trocha (que hoy es un importante frente de erosión), destruyó varios muros y recintos. Los subsectores I y III, por su estilo de paramento rústico tipo Killke, serían más antiguos. Del subsector II, netamente inka, quedan sólo bases de muros almohadillados; los paramentos fueron saqueados para cimentaciones y rellenos.

En el aspecto litológico se comprueba que las construcciones de los subsectores I y III emplearon el material del sitio (areniscas y lutitas con niveles de microconglomerados del grupo San Jerónimo), mientras que en el subsector II se usaron andesitas shoshoníticas traídas ya sea desde Rumicolca (unos 18 kilómetros al sureste) o de Huacoto, en el cerro Pachatusan, cuatro kilómetros al frente del sitio, pero unos 600 metros más arriba. Cabe remarcar que los inkas se mostraron muy poco proclives a usar areniscas y lutitas en sus construcciones, prefiriendo andesitas, calizas y dioritas.

El sitio en sí es estable; sin embargo, la evolución de las cárcavas, así como el avance de una reciente urbanización (La Encantada, posiblemente clandestina, pues se encuentra en plena área reservada), representan un peligro real de desestabilización, por los cortes de talud para nuevas construcciones y por la depredación de los muros de mampostería para su uso en construcciones modernas (fig. 10), como ya ocurrió en otras urbanizaciones del Cusco. El pastoreo y la erosión de senderos alteraron el régimen de escorrentía, afectando la estabilidad de las fundaciones. En los últimos años se nota un avance de los procesos de erosión de cárcavas, una de los cuales se desarrolla a unos cuarenta metros del límite sur del sitio arqueológico. 


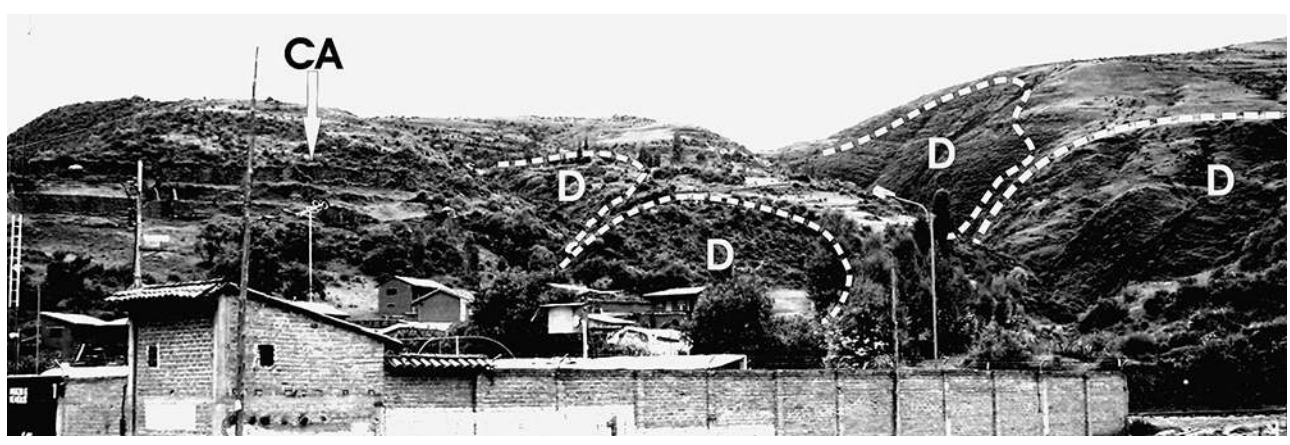

CA: ¿conjunto Inka-Killke?; D: deslizamientos. En primer plano, urbanización reciente en zona arqueológica reservada

Las medidas de prevención apuntarían a detener la urbanización, a controlar el vandalismo y el pastoreo, a tratar las cárcavas mediante rellenos, al reperfilaje de taludes, a la forestación y al control de erosión en la quebrada vecina.

Al frente de Sillkinchani, sobre la margen izquierda de la misma quebrada, existe otro pequeño conjunto arqueológico, Qontaymoqo, en muy mal estado de conservación, construido sobre materiales cuaternarios muy incompetentes (incluyendo niveles de arena y diatomitas), con pequeños deslizamientos que amenazan con destruir completamente el grupo. La situación se ve complicada por los planes de urbanización que existen para la zona, y por la extracción de materiales para adobe y jardinería.

\section{9. Tipón}

70 Situado en la vertiente sur del cerro Pachatusan, Tipón es, ante todo, conocido por su admirable sistema hidro-agrícola, que incluye los doce grandes y bellos terraplenes con que fue acondicionado el fondo de la quebrada, que señala el contacto del grupo Yuncaypata con los volcánicos Rumicolca, y que Angles (1988) califica como jardines.

Hay predominio de la arquitectura inka; empero, en el cercano grupo de Pukara se han identificado restos de las culturas Wari, K'illke y Lucre (INC-Cusco, 1994), lo cual implica una ocupación continua desde el periodo de los estados regionales. Además de su evidente función agrícola, se cree que pudo ser refugio del inka Yahuar Huacac (Pardo, 1957) que sería derrocado por su hijo, el inka Huiracocha durante el ataque de los chankas, según el relato de Garcilaso de la Vega. Por su estrecha puerta de entrada y la gran muralla de más de cinco kilómetros (que para varios arqueólogos podría ser pre-inka) que rodea a Tipón y otros grupos aledaños, se deduce también una función militar e, inclusive, algunos piensan que fue un lugar de acceso restringido, «sólo para gente de alto status social» (INC-Cusco, 1987).

72 Geológicamente se ubica en una zona de contacto del grupo Yuncaypata y de las andesitas shoshoníticas de la formación Rumicolca. En la base de la quebrada, y más arriba, aflora el grupo Mitu. Las rocas volcánicas están muy fracturadas por efecto de termocuplas, constituyendo frentes potenciales de derrumbe.

Parte de la muralla protectora y su estribo occidental descansan sobre el caos de rocas volcánicas con tendencia al derrumbe o la rodadura. Del mismo modo, los sectores de Sinkunakancka y Pitupujyo, situados también al borde del acantilado volcánico, están bajo cierto nivel de amenaza por derrumbe. Existen bloques derrumbados al pie del 
afloramiento volcánico, pero su cantidad y estado muestran que no se trata de eventos frecuentes ni masivos; pero, como la zona es sísmica, esas condiciones podrían cambiar en el futuro. En la cabecera del sitio, al norte, hacia Cruzmoqo, existen pequeños deslizamientos poco profundos, sin signos de actividad y asociados a caos rocosos de bloques volcánicos de la formación Rumicolca; al parecer los andenes contribuyeron a su estabilización.

Los andenes del lado oriental también fueron construidos sobre pequeños deslizamientos en afloramientos del Yuncaypata que sí muestran signos de actividad lenta, al punto que deformaron buena parte de los paramentos, obligando a su reconstrucción hace algo más de diez años. Es probable que parte del relleno de los andenes orientales y de los terraplenes del lado occidental haya provenido de esos deslizamientos.

Por un error de apreciación, muchas de las pantallas drenantes que existían tras los muros de piedra canteada fueron destruidas. Este error de interpretación surge del hecho de que tales pantallas - hechas de piedra no labrada y dispuestas en aparente desorden, dejando grandes intersticios para captar la escorrentía subsuperficial y las aguas de percolación- fueron confundidas con construcciones más antiguas, siendo consideradas sin mayor valor arquitectónico ni arqueológico, según la creencia de que los inkas tapaban paredes antiguas con sus propios muros, como parte del proceso de conquista-transculturación, y para ocultar los referentes de identidad de los pueblos sometidos. Posiblemente esta interpretación sea válida para algunos casos, pero no para Tipón, donde el análisis hidráulico y de estabilidad de rellenos y taludes prueba que tales paramentos rústicos fueron drenes y no muros de culturas pre-inkas. A esto se suma el hecho que detrás y al pie de los paramentos se hallan drenes subterráneos que captan y concentran el agua recogida por las pantallas drenantes y otros drenes intermedios. La mejor prueba de ello es que, al haber desaparecido o ser modificadas esas pantallas drenantes, el empuje del deslizamiento y de los rellenos no cohesivos ha comenzado a deformar nuevamente los muros, apareciendo además eflorescencias de sulfatos, carbonatos y óxidos sobre la superficie externa de los sillares.

En resumen, los niveles de peligro-vulnerabilidad en Tipón son bajos y fácilmente manejables. Sin embargo, los andenes orientales y los sitios de Sinkunakancha y Pitupujyo merecen cierta atención, por la susceptibilidad a derrumbes que presentan. Un elemento moderno que sí requiere de vigilancia y obras de tratamiento es la carretera de acceso, donde los derrumbes han causado varios accidentes y podrían ser un indicador de aceleración de un deslizamiento rocoso que existe en la ladera suroriental vecina al núcleo del parque arqueológico.

De otro lado, las quebradas de los riachuelos Huaycconan y Jucuchahuaycco (fig. 11), que limitan por el noroeste y noreste con el parque arqueológico de Tipón, presentan varios grandes deslizamientos muy activos - que involucran especialmente materiales del grupo Yuncaypata-, que contribuyen a generar continuos huaycos que afectan casi anualmente al pueblo de Choquepata (que tiene algunos restos de muros, canales y andenes inkas, además de su hermoso templo indígena y algunas casas posiblemente coloniales). Todo esto ha obligado a la reubicación parcial del pueblo en un nuevo asentamiento sobre la carretera Cusco-Arequipa. 
Figura 11 - Tipón

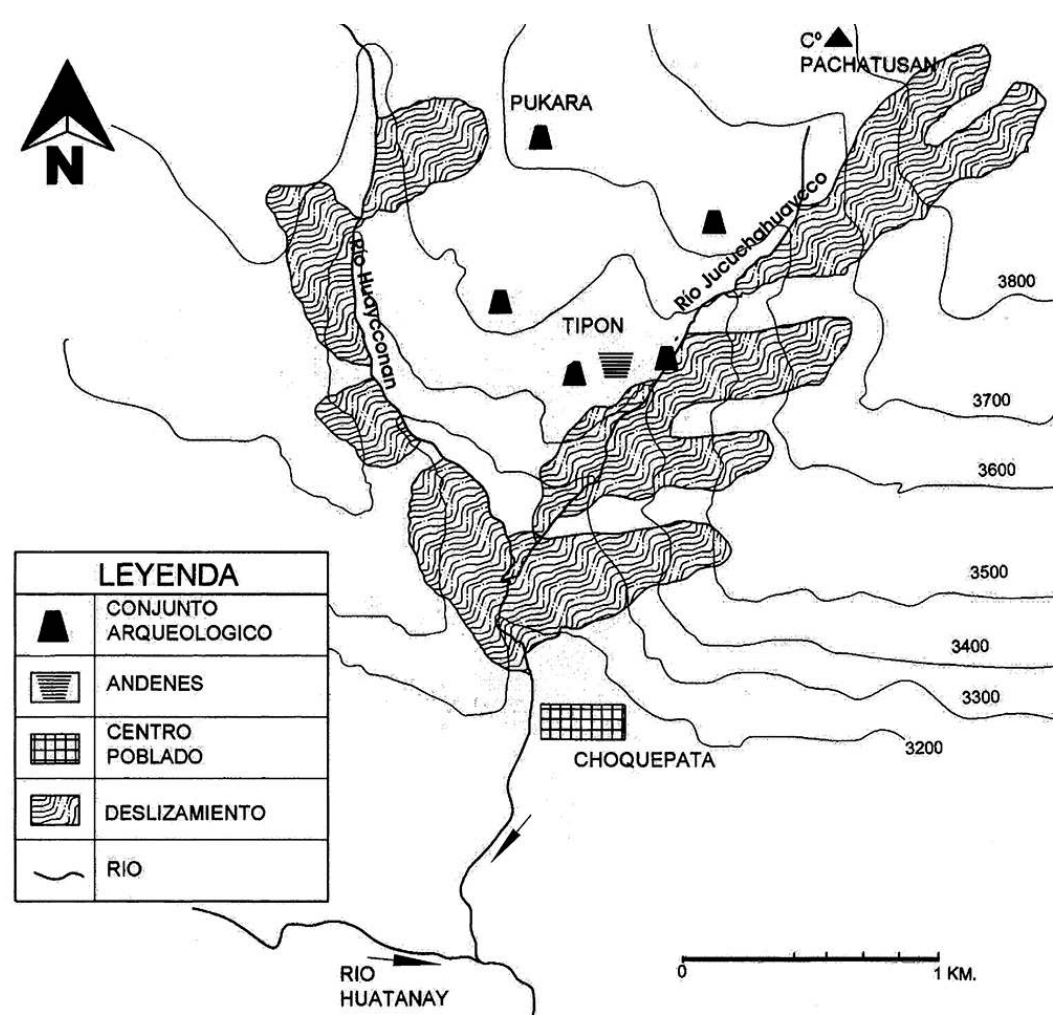

Esquema geodinámico

\section{10. Urpikancha}

Este conjunto comprende pequeños asentamientos urbanos y andenes, los cuales son de dos tipos: los inferiores (amplios, de mejor factura, con mampostería almohadillada bien labrada, ocupan una explanada cercana a la laguna) y los andenes de ladera (dos sistemas separados, uno sobre Urpikancha y otro más cerca de los restos de Tamboraqay, son algo más rústicos). Resulta claro que todo el relleno de estos andenes es alóctono, pues prácticamente no existen suelos en estos roquedos y canchales. La parte de habitación se sitúa sobre una terraza formada por las rocas volcánicas de la formación Rumicolca, muy cerca de la laguna de Muyna o Huacarpay. Existen, además, otras construcciones dispersas tipo depósito o de vigilancia.

Los andenes se ubican hacia el Este, sobre un talud de derrubios formado por la desintegración mecánica de las shoshonitas y que han adquirido un comportamiento de deslizamiento rocoso muy lento (fig. 12). De lejos, el conjunto detrítico tiene una apariencia que se asemeja en algún modo a la de los canchales de gelifracción que se forman en las jalcas. Parte de esta masa inestable ha sufrido aceleración hace pocos años, desplazando cierta cantidad de derrubios cerca al sistema sur de andenerías, sobre el actual albergue turístico. Por su alta permeabilidad, se descarta que los movimientos de esta masa inestable sean inducidos por variaciones en el nivel freático, por lo que es más probable que los episodios de aceleración o de reactivación respondan, sobre todo, a sacudidas sísmicas, a intervenciones humanas (cortes para caminos y explotación de agregados) o al tránsito de animales pesados. 
Figura 12 - Parte del conjunto de Urpikancha

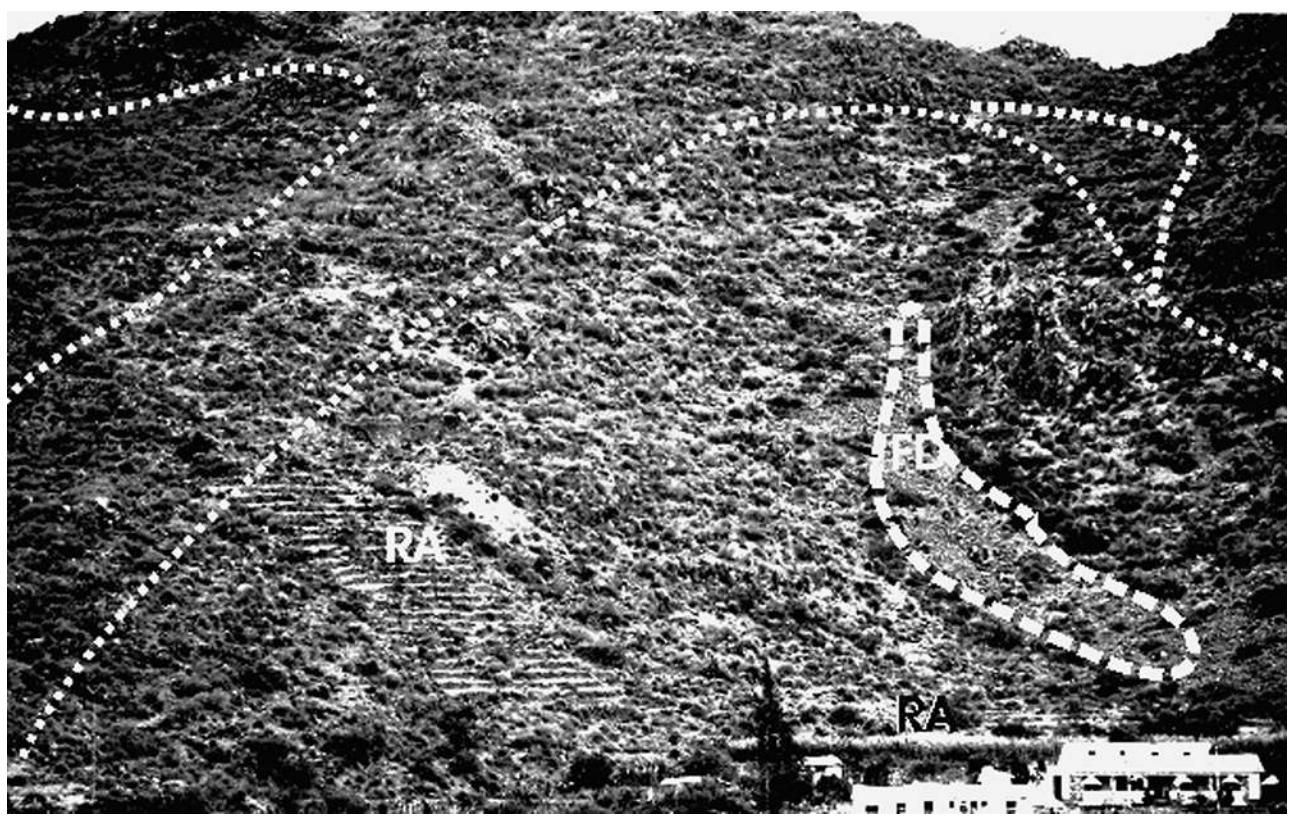

Línea punteada: límite probable de los deslizamientos rocosos lentos. RA: restos arqueológicos. Línea entrecortada: restos del flujo seco de detritos por reactivación del deslizamiento. Abajo, el albergue turístico

80 Por su constitución (masa de derrubios) el deslizamiento se comporta como un agregado friccionante. En caso de sismo, por la granulometría gruesa y la virtual ausencia de agua intersticial, la distancia de desplazamiento sería pequeña, aunque, de todos modos, involucraría al menos a parte o al total de los andenes del sector sur y al albergue turístico-recreativo que allí existe.

81 En la zona de Minaspata, en el ápice sud-occidental del afloramiento de shoshonitas, hubo explotaciones mineras de poca escala; no se conoce el impacto de los socavones sobre la estabilidad general del cuerpo de roca volcánica. Por la existencia de restos arqueológicos, valdría la pena evaluar el estado de tales labores mineras, que conllevan cierto potencial de colapso.

82 El drenaje natural es muy eficiente, lo cual (al igual que lo reducido de la cuenca de recepción) explica la muy escasa actividad del deslizamiento y la poca distorsión de los muros. La situación podría cambiar en caso de realizarse cortes de talud o extracción de materiales (actividad que ya se practicó en el pasado), o por afluencia masiva de turistas, pues la zona es parte de un nuevo circuito turístico.

\section{11. Pikillaqta}

83 Hasta los años 60 del siglo pasado, se pensaba que Pikillaqta era una construcción inka, una «ciudad de pósitos y bastimentos» (Harth-Terré, 1959). Pardo (1957), aunque con reservas, lanza la hipótesis de que perteneció a la época auroral de los inkas. Hoy se sabe que fue una ciudad y un centro administrativo Wari (o Wari-Chanka, como los denomina Barreda Murillo), tal vez el más importante de la región. Esta ciudad, asentada sobre alrededor de ochenta hectáreas (un área superior a la del núcleo del Cusco inkaiko, según la comparación de Gasparini \& Margolies), consta de más de 500 
edificaciones de mampostería rústica con mortero y revoques de barro, recubiertos a su vez por un estuco de yeso (Barreda, 1995).

Las funciones de Pikillaqta son objeto de múltiples especulaciones y disentimientos: por la aparente ausencia de puertas y ventanas se pensó que eran depósitos. Sanders (citado por McEwan, 1982) lo calificó como manicomio o cárcel. McEwan (1982) dice que «Fue construido probablemente como residencia de élites políticos y religiosos (sic) quienes administraban parte del imperio Wari asentado en la sierra sur». Los estudios más recientes prueban que fue una ciudad completa. Lumbreras (2000) la pone como ejemplo de la «racionalidad de esta forma de vida urbana [...]».

Este gran orden urbanístico se condice con las medidas de prevención en materia de drenajes y de elección de un sitio relativamente seguro, alejado de frentes de erosión y de inestabilidad evidente. En general, Pikillaqta en sí no presenta signos de peligro geodinámico ni torrencial, por estar edificada sobre una meseta $\mathrm{y}$, a pesar del alto contenido de sulfatos que hay en los suelos, no está mayormente amenazada por procesos de karstificación, debido al buen avenamiento natural de la zona y al funciona-miento eficaz de los sistemas de drenaje precolombinos. Informes del antiguo Patro-nato Departamental de Arqueología del Cusco mencionan constantes inundaciones que contribuían a derrumbar muros de esta ciudadela (Velasco, 1972). Consideramos que tales problemas correspondían más bien a anegamientos derivados de la falta de limpieza de los drenes.

En cambio, hacia el norte del conjunto arqueológico, en el cerro Jatunbalcon (denominado Pukaccasa en la hoja topográfica 28-s (o 2543), 1/100 000, del Instituto Geográfico Nacional), existe un antiguo deslizamiento subactivo, con una superficie de algo más de dos kilómetros cuadrados, que afecta a rocas evaporíticas y pelíticas con niveles de calizas del grupo Yuncaypata (fig. 13). Sólo los bloques situados hacia el sureste, en la bajada a Piñipampa, muestran signos de actividad lenta y fuerte erosión. Por el contrario, el compartimiento que da hacia Pikillaqta parece casi inactivo. Otro compartimiento, situado detrás del conjunto arqueológico, sí presenta mayores signos de reactivación (fig. 14), con inicio de cárcavas. Sin embargo, el peligro inducido no es muy grande, por las condiciones morfológicas de esta zona. 
Figura 13 - Esquema geodinámico de Pikillaqta-Rumicolca

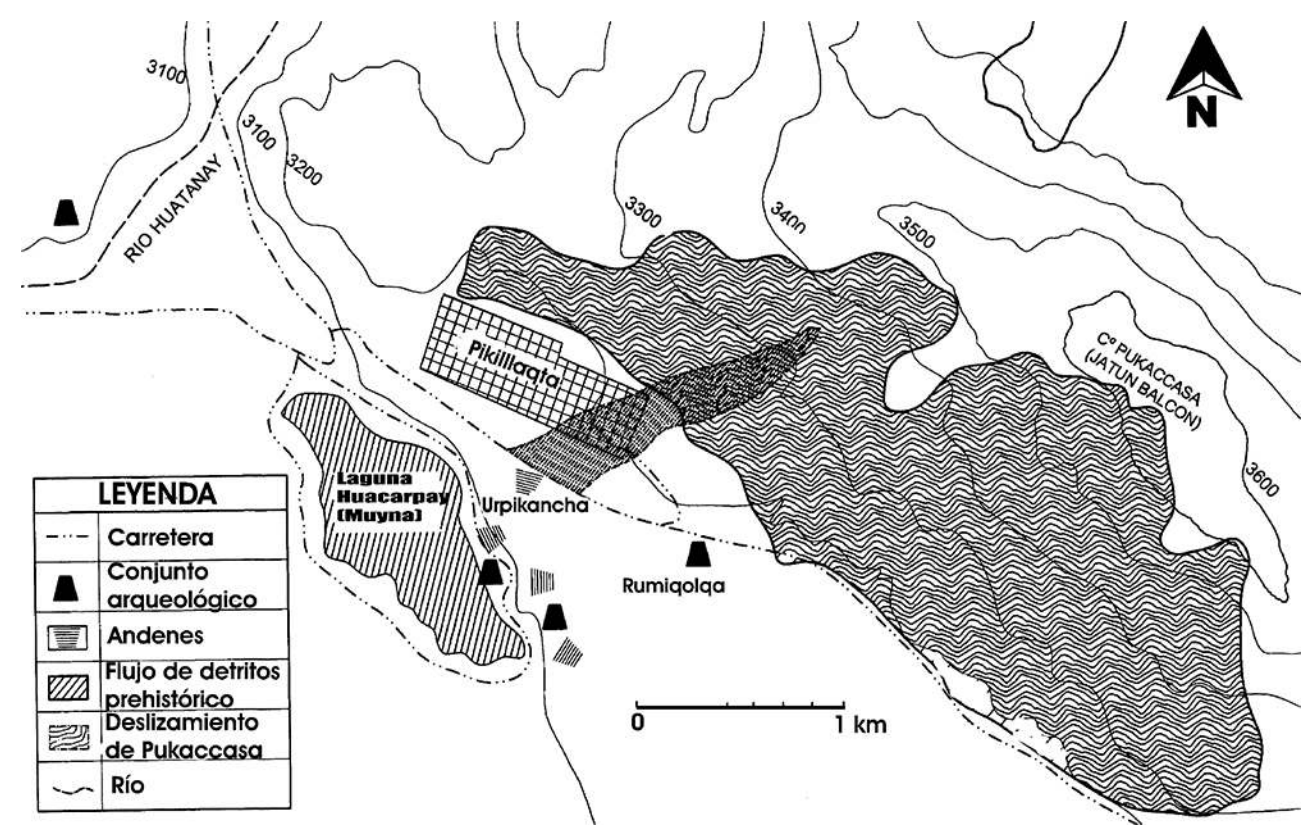

Figura 14 - Sitio arqueológico Pikillaqta

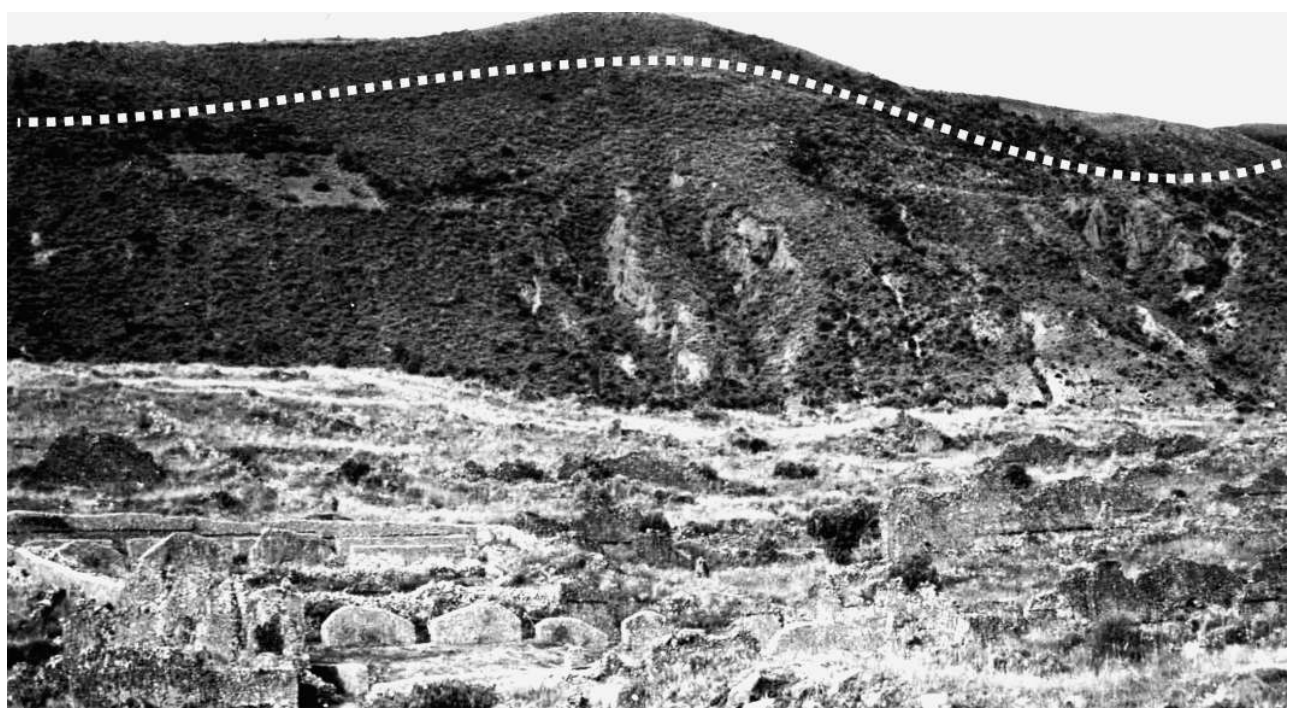

En primer plano: parte del núcleo principal de Pikillaqta. Al fondo (línea punteada), parte del deslizamiento del cerro Pukaccasa, con signos de erosión y reactivación

$87 \mathrm{Al}$ parecer las lavas andesíticas de los eventos volcánicos del Plio-Pleistoceno (formación Rumicolca) actuaron como una cuña que retuvo parte del pie de esta ladera inestable, con lo cual el mecanismo de deslizamiento habría sido atenuado en el lado oeste del macizo, quedando una actividad residual de inestabilidad tipo sagging (deformaciones plásticas sin agrietamiento, fenómeno común en este tipo de materiales), la que no representa mayor peligro inmediato para la zona. El análisis de fotos aéreas muestra trazas de un antiguo flujo proveniente de dicho deslizamiento, por lo que una porción menor de la ciudadela está construida sobre parte de un muy antiguo cono aluvial que tuvo origen en un episodio de aceleración paroxística del bloque occidental del deslizamiento. 
Se puede afirmar que subsiste cierto nivel, muy bajo, de peligro por deslizamiento o por flujos que podrían afectar al menos parte del lado oriental del conjunto arqueológico. Esto se vería favorecido por el desarrollo de cárcavas muy activas al pie del flanco sur del cerro Pukaccasa, a lo largo y cerca a la carretera Cusco-Arequipa, y por la explotación artesanal, no planificada ni controlada, de canteras de yeso que estarían reactivando parte del deslizamiento mayor, formando frentes erosivos cuya regresión podría alcanzar la zona de las grandes murallas que protegen la ciudadela.

En resumen, Pikillaqta, aunque no está bajo una amenaza importante, requiere trabajos de evaluación de procesos kársticos subterráneos, control de cárcavas, de las explotaciones de yeso, de la escorrentía superficial, un drenaje controlado de taludes y tratamiento de torrenteras.

\section{12. Rumicolca}

90 Esta portada o fortín o aduana de bella factura inka, llamada también «reducto» por Harth Terré (1959), debió tener varias funciones, siendo primordial la de seguridad y control, por tratarse del acceso natural hacia el valle del Cusco en un abra estrecha situada sobre el contacto del grupo Yuncaypata con las rocas volcánicas de la formación Rumicolca. La gran muralla que cerraba el abra servía también como acueducto-puente, para llevar el agua del río Lucre hacia Pikillaqta y otros centros poblados menores. Sobre este punto McEwan (1982) plantea sus dudas, pues dice que la cota del acueducto es inferior a la de Pikillaqta.

91 Aunque el conjunto está fundado sobre suelos con abundante contenido de yeso, los eventuales problemas de disolución de tales sulfatos parecen estar atenuados por el buen drenaje natural y la relativa sequedad de la zona. El conjunto de Rumicolca en sí no presenta problemas geodinámicos; solo en el estribo sur de la muralla principal se ha identificado un pequeño deslizamiento rocoso, en el cual se observa un proceso de formación de una nueva superficie de ruptura de unos siete a ocho metros de profundidad, siendo también propicio a formar derrumbes. Las masas actualmente inestables (conos de derrubios volcánicos y pequeño deslizamiento rocoso en progresión) no ponen en peligro directo las construcciones. Sin embargo, es necesario vigilar la evolución del nuevo deslizamiento que viene separando un importante bloque de roca en el estribo sur (fig. 15) y cuyo colapso podría afectar parte del acueducto y el soporte lateral del muro sur de la portada. La extracción clandestina de ripios y piedra para construc-ción contribuye a una mayor inestabilidad de dicho talud. 


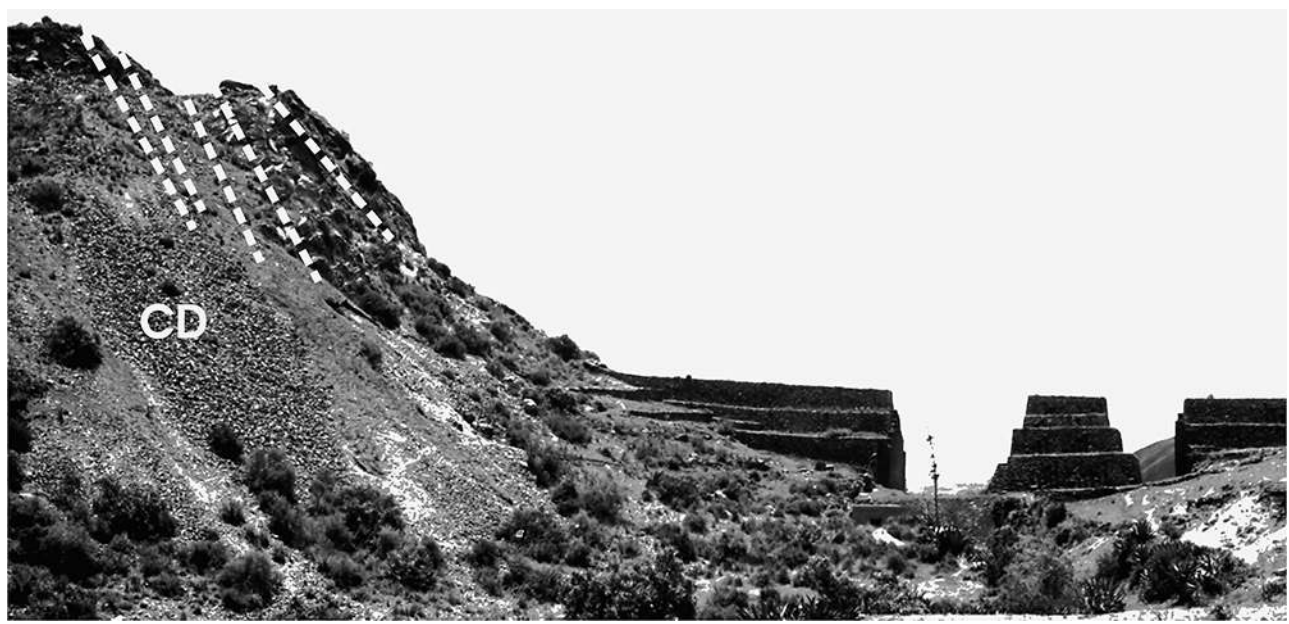

A la izquierda, el deslizamiento rocoso activo con nuevos planos de ruptura en desarrollo (líneas entrecortadas) y conos activos de talus (CD)

92 Al igual que para Pikillaqta, aunque con mayor nivel de peli-grosidad, Rumicolca está amenazada por las explotaciones artesanales de yeso en el cerro Pukaccasa, sobre el ya mencionado deslizamiento que cubre su flanco sur. Tales explotaciones, junto a la actividad plástica residual del deslizamiento, podrían inducir su reactivación parcial o general, con formación de flujos de lodo o de detritos que, eventualmente, en caso de episodio mayor, podrían enterrar parte del conjunto arqueológico. Como ya se indicó, los cuerpos secundarios orientales de este gran deslizamiento son activos, algunos en fase de aceleración. El problema se ve agravado por el corte de la carretera y el rápido desarrollo de varias cárcavas al pie del deslizamiento y en la zona de contacto con las rocas volcánicas.

\section{Balance de puntos críticos}

El grupo de Choquekiraopujyo y otros conjuntos menores vecinos situados especialmente sobre la margen izquierda del río Kachimayo, son los más expuestos a los deslizamientos y procesos de erosión mecánica y química. En orden de importancia, siguen algunos sectores de Saqsayhuaman, Pukapukara y de la cuenca de Chakán, también amenazados principalmente por deslizamientos y karstificación. Aquí, los trabajos de prevención, auscultación instrumental y tratamiento tienen que ser de largo aliento y de gran envergadura, por la naturaleza, dimensión y grado de evolución de los fenómenos peligrosos.

En los demás sitios analizados, los niveles de peligrosidad son menores y bastarían trabajos más o menos sencillos de tratamiento para reducir la susceptibilidad o la actividad de los fenómenos peligrosos. En la mayoría de casos de deslizamiento se impone la necesidad de establecer sistemas de auscultación o monitoreo instrumental permanente. En otros, el nivel de peligro puede ser reducido mediante sencillos trabajos de «desquinche» de taludes, drenaje planificado, tratamiento de cárcavas, reconstitución de drenes y canales prehispánicos, control del tránsito de personas, vehículos y animales, etc. 


\section{BIBLIOGRAFÍA}

ANGLES, V., 1988 - Historia del Cusco incaico, Tomo I, 535 p; Tomo II, 612 p.; Lima: INDUSTRIALgráfica.

ANGLES, V., 1990 - Sacsayhuaman, portento arquitectónico, 184 p.; Lima: INDUSTRIALgráfica. BARREDA, L., 1995 - Cuzco. Historia y arqueología pre-inka, 99 p.; Cusco: Instituto de Arqueología Andina Machupiqchu.

BAUER, B., 2000 - El espacio sagrado de los Incas, 239 p.; Cusco: Centro Bartolomé de las Casas.

CABRERA, J., 1988 - Néotectonique et sismotectonique dans la Cordillère Andine au niveau du changement de géométrie de la subduction : la région de Cuzco (Pérou), 275 p.; Paris: Université de Paris-Sud.

CARREÑO, R., 1997a - Instability phenomena and Inca monuments. A preliminary diagnostic on some Peruvian cases. In: International Symposium on Natural Disaster Prediction and Management Proceedings: 277-292; Kyoto.

CARREÑO, R., 1997b - Patrimonio cultural y terrenos inestables. Boletín PROEPTI-Noticias, 8: 1-3; Cusco.

CARREÑO, R., 1998a - Zonas críticas en el valle del Cusco. Boletín PROEPTI-Noticias, 12: 6-8; Cusco.

CARREÑO, R., 1998b - Inventario de deslizamientos, valles de Cusco y Sagrado de los Inkas 23 p.; Cusco: Mapas e informe interno PROEPTI-EPFL (Versión ampliada y detallada en preparación).

CIEZA DE LEÓN, P., 1977 [1553] - El señorío de los Incas, 262 p.; Lima: Editorial Universo. Colección Autores Peruanos, vol. 45.

CUMPA, C., 2001 - Proyecto de investigación arqueológica Sillkinchani, 32 p.; Cusco: Instituto Nacional de Cultura.

FLEMING, R. W., MONITION, L. \& NOVOSAD, S., 1986 - Riesgos de crecidas y deslizamientos en la ciudad del Cusco. In: Problemática urbana, vivienda y tecnología mejorada en el departamento del Cusco: 145-185; Cusco: IIUN.

HARTH-TERRÉ, E., 1959 - Piki-Llacta, ciudad de pósitos y bastimentos. Revista del Museo e Instituto Arqueológico del Cuzco, 18: 41-56; Cusco.

HUAYCOCHEA, F., 1994 - Qolqas, bancos de reserva andinos: almacenes inkas. Arqueología de Qolqas, 283 p.; Cusco: UNSAAC.

INSTITUTO NACIONAL DE CULTURA-CUSCO, 1987 - Conjunto arqueológico de Tipón. Programación de obra 1987; Cusco: INC-C.

INSTITUTO NACIONAL DE CULTURA-CUSCO, 1994 - Conservación Parque arqueológico de Tipón. Informe anual de obra 1994; Cusco: INC-C.

KALAFATOVICH, C., 1957 - Edad de las calizas de la formación Yuncaypata, Cuzco. Boletín de la Sociedad Geológica del Perú, 32: 127-139; Lima.

LUMBRERAS, L., 2000 - El Imperio Wari, 62 p.; Lima: IFEA-Lluvia editores. Las formas históricas del Perú, vol. 8.

McEWAN, G., 1982 - Investigaciones en Pikillacta - Informe final, 70 p.; Cusco: Proyecto Pikillacta. MENDÍVIL, S. \& DÁVILA, D., 1994 - Geología de los cuadrángulos de Cuzco y Livitaca, 115 p.; Lima: INGEMMET. Bol. $n^{\circ}$ 52, serie A: Carta Geológica Nacional. 
MORMONTOY, A., 1995 - Investigaciones arqueológicas en Sillkinchani, San Jerónimo - Cusco. Andes, revista de la facultad de Ciencias Sociales, 1: 77-96; Cusco: UNSAAC.

PARDO, L., 1957 - Historia y arqueología del Cuzco, 679 p.; Lima: Colegio Militar Leoncio Prado. 2 tomos.

PARDO, L., LADRÓN DE GUEVARA, O. \& OBERTI, Í., 1972 - Informe Saqsaywaman. Saqsaywaman, Revista del Patronato departamental de arqueología del Cusco, 2: 235-266; Cusco.

PROEPTI-EPFL, 1999 - Monitoreo instrumental de algunos deslizamientos de Cusco y Urubamba, 22 p.; Cusco. PROEPTI-EPFL. Informe interno.

PROEPTI-EPFL, 2001 - Proyecto de estudio y prevención de desastres relacionados a terrenos inestables en la región de Cusco-Perú - Informe final, 79 p. + mapas y anexos; Lausanne: École Polytechnique Fédérale de Lausanne.

VELASCO QUINTANILLA, I., 1972 - Memoria. Trabajos realizados de 1929 a 1972. Patronato departamental de arqueología del Cusco. Saqsaywaman, Revista del Patronato departamental de arqueología del Cusco, 2: 267-291; Cusco.

ZECENARRO, G., 2001 - Arquitectura arqueológica en la quebrada de Thanpumach'ay, 301 p.; Cusco: Municipalidad Provincial del Cusco.

\section{NOTAS}

*. Esta es una contribución al Programa IGCP-425 Patrimonio cultural y deslizamientos y al Internacional Programme on Landslides (IPL).

\section{RESÚMENES}

De los numerosos conjuntos arqueológicos prehispánicos existentes en el valle del Huatanay, Cusco, varios se encuentran amenazados o están siendo destruidos por fenómenos de geodinámica externa (deslizamientos, derrumbes, lavas torrenciales y karstificación y erosión). La mayoría de estos procesos son de carácter lento, pero muchos muestran signos de aceleración debido a su dinámica natural o por intervenciones humanas: la falta de mantenimiento, la depredación, las actividades agropecuarias y forestales inapropiadas, la urbanización y el turismo no controlados.

Parmi les nombreux sites archéologiques pré-hispaniques de la vallée de Huatanay, Cusco, plusieurs sont menacés ou en train d'être détruits par des phénomènes de géodynamique externe (glissements de terrain, éboulements, alluvions torrentielles, karstification et érosion). La plupart de ces processus ont une dynamique lente, mais plusieurs d'entre eux montrent des signes d'accélération, due à leur dynamique propre ou sont aggravés par des interventions humaines : le manque de maintenance, la déprédation, les activités agricoles et forestières inadéquates, l'urbanisation et le tourisme non contrôlés. 
Of the numerous Prehispanic archaeological complexes located in the Huatanay Valley Cusco, several are threatened or are being destroyed by external geodynamics phenomena (landslides, rock falls, lava flows, karstification and erosion). Most of these processes are slow, but many of them show signs of acceleration, due to their natural dynamics or by humain intervention: lack of maintenance, depredation, inappropriate agricultural and forestry activities, and uncontrolled urbanization and tourism.

\section{ÍNDICE}

Keywords: Cusco valley, external geodynamics, archaeological heritage, landslides, rock falls, erosion, karstification, danger-vulnerability

Mots-clés: Vallée du Huatanay, Cusco, géodynamique externe, glissement de terrain, éboulement, érosion, karstification, aléa-vulnérabilité, patrimoine archéologique

Palabras claves: Valle del Huatanay, Cusco, geodinámica externa, deslizamientos, derrumbes, erosión, karstificación, peligro-vulnerabilidad, patrimonio arqueológico

\section{AUTOR}

\section{RAÚL CARREÑO COLLATUPA}

GRUDEC AYAR, Apartado postal 638, Cusco-PERÚ. Correo electrónico: raulcarreno@ayar.org.pe 